\title{
RPAS-Based Framework for Simplified Seismic Risk Assessment of Italian RC-Bridges
}

\author{
Andrea Nettis *(1), Mirko Saponaro ${ }^{(1)}$ and Massimo Nanna ${ }^{(1)}$ \\ Department of Civil, Environmental, Land, Construction and Chemistry (DICATECh), Politecnico di Bari, \\ 70125 Bari, Italy; mirko.saponaro@poliba.it (M.S.); m.nanna@studenti.poliba.it (M.N.) \\ * Correspondence: andrea.nettis@poliba.it
}

Received: 31 July 2020; Accepted: 26 August 2020; Published: 28 August 2020

\begin{abstract}
Existing reinforced concrete (RC) bridges that were designed in the decades between 1950 and 1990 exhibit inadequate structural safety with reference to both traffic loads and hazard conditions. Competent authorities are planning extensive inspections to collect data about these structures and to address retrofit interventions. In this context, Remotely Piloted Aircraft Systems (RPASs) represent a prospect to facilitate in-situ inspections, reducing time, cost and risk for the operators. A practice-oriented methodology to perform RPAS-based surveys is described. After that, a workflow to perform an in-situ RPAS inspection oriented to a photogrammetric data extraction is discussed. With the aim to connect the advantages of the RPAS technologies to the seismic risk assessment of bridges, a simplified mechanic-based procedure is described, oriented to map the structural risk in road networks and support prioritization strategies. A six-span RC bridge of the Basilicata road network, representing a typical Italian bridge typology is selected to practically describe the operating steps of the RPAS inspection and of the simplified seismic risk assessment approach.
\end{abstract}

Keywords: RPAS inspection; photogrammetry; BIM; existing bridges; seismic risk; structural safety

\section{Introduction}

In most developed countries, existing roadway and railway bridges built between the 1950s and 1990s exhibit structural deficiencies that could limit the safety and serviceability of the transportation networks. Most of these structures show severe degradation conditions due to the absence of an adequate theoretical knowledge on the durability of concrete and steel, and were designed with regulatory requirements less demanding in terms of structural performance than the current ones. For instance, in the operating environment today, the past regulatory codes have proved to be highly deficient if the design traffic loads are compared to the current traffic demand, and when considering the performance design in relation to natural hazards, such as earthquakes. This highlights the vulnerability of the existing bridge portfolios, which could affect the resilience of entire areas in a post-event emergency phase. Indeed, this issue is increasingly perceived by road managers and public administrations. Currently, transport authorities express a strong need to plan extended and operative strategies to assess the condition of the existing bridges heritage, to identify the criticalities and to address retrofit interventions. A recent report by the Italian provinces states that almost $50 \%$ of bridges and galleries require targeted diagnostic surveys and structural assessment processes to define their remaining service life. In Italy, the guidelines for the inspection and assessment of bridges [1] have been proposed after recent dramatic bridge collapses, such as the failure of the Polcevera bridge in Genova. Guidelines based on this theme are currently in force in other countries such as Germany and the USA [2]. In this context, competent authorities are promoting tailored operating plan systems to investigate the degradation conditions and the structural assessment of existing bridges. General inspection campaigns are programed in order to include structural safety 
data in the bridge management systems. Given the high number of structures to be analyzed, efficient and simplified procedures to perform a quick and refined data collection and structural assessment are strongly needed.

Particularly, knowledge-data about existing structures are often poorly included (or not included) in bridge management databases. The process aimed at the collection and digitalization of design documents and blueprints has just started and often is hindered by the lack of this type of data, which are lost or stored in inaccessible archives [3], requiring the retrieval of data from different sources and using alternative tools [4]. As an example, in past decades a relevant reorganization in the management of road networks has been carried out in Italy. The knowledge-data of some roads, which were re-classified, were not transmitted between the different owners, leading to strongly fragmented databases. In these cases, a refined data collection with in-situ surveys and diagnostic tests (destructive and nondestructive) is necessary.

Conventional inspections are carried out by trained operators that visually assess the condition of the bridge, who manually draw up inspection documents and evaluate the condition of the bridge with a determined degree of subjectivity. These data are then allocated in bridge management databases to be a reference for future inspections. Traditional in-situ surveys generally require the employment of provisional structures that increase the inspection time and demand traffic limitations and service disruption. A revolutionary change in the conventional approach is determined by innovative methodologies that use sensors for structural health monitoring and innovative remote-sensing non-contact techniques, together with the Building Information Model (BIM) paradigm [5-10]. These components push toward comprehensive automatic workflows that start with data collection and processing and yield directly to quantitative structural assessment.

Remotely Piloted Aircraft Systems (RPASs), generally labelled as drones, represent an important resource in this framework. These are small autonomous flight vehicles equipped with low-cost RGB cameras or other more sophisticated sensors (e.g., multispectral and thermal cameras; LiDAR technologies). Several research works investigated robust methodologies to perform effective RPAS-based inspections on bridges or civil structures [11,12]. These are aimed at collecting precise and targeted details to be integrated with other information measured on site. In the U.S. context, the issue of the structural safety of existing bridges has been widely faced in the last decade and differing departments of transportation are promoting several research projects to exploit the entire potential of RPASs for inspecting civil structures [13]. In the field of visual-based inspections, Chan at al. [14] proposed a review on the advantages and criticalities of RPAS-based inspections on bridges, analyzing different aspects, such as the minimum technical requirements of the drones, restrictions of the regulatory codes and cost-benefits analyses. They claim that a RPAS-based inspection can significantly reduce the time and cost of the survey. Moreover, RPAS can strongly increase the safety of the operators which usually deal with problematic boundary conditions linked to the traffic or the environment of the bridge. Seo et al. [15] evaluated the effectiveness of a drone-based inspection on a three-span timber bridge, analyzing the image quality and the potentialities in damage identification, comparing the results with a conventional visual inspection. Otero et al. [16] discussed the influence of different RPAS features such as manoeuvrability, payload, size, adaptability, etc., that are decisive for an accurate field inspection.

Large potentials are linked to the use of drones together with Computer Vision (CV) algorithms, namely the Structure from Motion (SfM) techniques, capable of returning accurate three-dimensional models suitable for virtual ex-situ inspection. Furthermore, several studies focus on the quantitative evaluation of damage conditions through algorithms of damage detection and crack measurement based on 3D point cloud models [17]. Various applications turn to the extraction of geometrical data and the automatic classification of bridge components. The work by Khaloo et al. [18] was aimed at testing 3D-photogrametry techniques to build a 3D dense point cloud of a pedestrian timber truss bridge located in Alaska, starting from drone imagery. The authors stated that the obtained model outperforms (in terms of accuracy and completeness of the details) the one achieved by means of terrestrial laser 
scanning-inspections. Recently, Morgenthal et al. [2] proposed a comprehensive and automated framework for the condition assessment of bridges based on high resolution 3D models built using RPAS-based imagery. Crack detections and damage recognition are performed using machine-learning techniques. The authors claimed that automatic structural assessment algorithms considering both the degradation condition and the mechanical quantification of structural deformations should follow RPAS-based inspections. They performed a calibration of a baseline Finite Element Model (FEM) based on the structural deformations measured using the 3D point cloud model. It is worth mentioning that, as claimed in [2], the natural remainder of the data collection phase is a quantitative structural assessment. It usually requires a finite element modeling phase together with an accurate numerical analysis to evaluate the structural bearing capacity in terms of traffic loads, remaining service-life, and vulnerability to given hazard condition such as earthquakes.

The theme of the automatic definition of FEMs from the point cloud achieved with remote sensing technologies has been faced in literature $[19,20]$. This focus on algorithms is feasible to perform a simplification of the point cloud model, extracting the features useful to finite element modeling. Actually, this task may represent a hard challenge for bridge modeling, since these structures, although characterized by a simple structural scheme, are composed by members having particularly different mechanical behaviors (e.g., bearing devices, shear keys). Moreover, structural analysis based on an FEM approach requires a considerable amount of time and computational effort, particularly if non-linear analyses should be performed for seismic vulnerability evaluation purposes. Indeed, these strategies can be difficultly applied for seismic vulnerability assessment of high-populated bridge portfolios, unless resorting to robust automated workflows and soaring computational capabilities [3]. Dealing with the seismic risk, simplified procedures to perform structural vulnerability assessment of portfolios of structures are of increasing interest in the scientific community. These are generally based on geometrical and structural data collected by completing digital data forms through an in-situ inspection. The employment of a RPAS-based data collection can particularly facilitate this process due to safer, targeted, more economical, and timely surveys.

Given the remarks collected in the literature, an innovative practice-oriented methodology to perform close-range RPAS-based surveys is described in this work, adapted to the characteristics of the Italian context. The process is oriented to the development of a 3D dense point cloud model that is feasible to address further BIM modeling phase to allocate structural data for multi-temporal surveys. The surveys yield to a complete geometrical characterization of the investigated structure, which is the input for a simplified procedure for estimating the seismic risk. The latter is based on an innovative displacement-based algorithm and simplified mechanical models, that require very low computational effort with respect to FEM analysis. It is based on the geometrical input data, collected in a table spreadsheet, which can be easily obtained by means of a geometrical (automated or manual) classification of 3D point cloud model. The general workflow is outlined in Sections 2 and 3 consistently with the prescriptions of the current regulatory framework. Section 4 instead describes the application of this method to the case study. Finally, the learned observations are discussed, highlighting possible critical issues and future proposals in Section 5, Conclusions.

The presented methodology, from the RPAS-based data collection to the seismic risk assessment, is applied on a six-span Reinforced Concrete $(\mathrm{RC})$ bridge of the Basilicata road network, representing a typical Italian bridge typology. In the process automation prospectus, the proposed work highlights the advantages and limitations that have emerged from this new approach applied to bridge management and control, and the need to structure a methodical programme to test and validate several types of structures.

\section{RPAS-Based Inspection Methodology}

\subsection{RPAS Flight Planning and Data Collection}

Several leading companies in the infrastructure sector introduced innovative methods of bridges inspection in recent years, with the aim of overcoming various difficulties caused by the increasing 
scarcity of financial resources, and also by the inaccessibility of most sites. With the technological advent of Remotely Piloted Aircraft Systems (RPASs) it is possible to overcome various difficulties, thanks to their versatility, optimizing management and maintenance times and costs, in order to harmonize targeted intervention solutions.

The remote piloted technologies operation in Italian airspace is governed by the ENAC Regulations Issues No. 3 dated 11 November 2019 [21] which implements the European Commission Regulation (EU) 2019/947 of 24 May 2019 [22]. The latter was also recently adopted in different regulation codes by other European countries. Given the operating conditions constrained by the public and strategic nature of the infrastructure, the monitoring activity should include risks management and careful planning of critical operations in the field (airspace limitations, weather, organigram and tasks, etc.).

In the planning phase of the mission, the mode of execution and the method of classification of the structural elements is defined [11]. The inspection of the piers, deck-substructure connection systems, pier caps, underside and outside of the deck is foreseen. First, access points are identified to allow pilots to operate close to the bridge and establish the various take-off points.

In general, the most suitable aircrafts for bridge inspection are multicopters, equipped with a Global Navigation Satellite System (GNSS) receiver and a suitable infrared sensor system capable of keeping obstacles at a safe distance [23]. For operation below the deck, the losing of GNSS signal can be resolved via a radio link in Real Time Kinematic (RTK) mode with a master station nearby, equipping the aircraft with a zenithal camera for the intrados inspection. Infrared no-impact sensors are essential for flying in limited-space zone to inspect small-size structural components (such as the bearing devices) or assess the degradation conditions in critical "hidden" parts (such as the support of the girders) which are very sensitive to cracking or moisture phenomena and assume a critical role in the structural safety. In order to overcome the turbulent effects of the wind near and under the bridge, if not in possession of multi rotor aircraft with head-mounted cameras and appropriate anti-collision sensors, it is preferable to acquire the images in hovering mode or using the zoom function to keep the vehicle at a suitable distance.

For the survey of the outer casing of the structure, a manual flight can be made or, given the practicability of the structure itself and the context (natural obstacles, electrical cables, etc.), an automatic route by waypoint (Figure 1) can be planned. Optimizing times and routes, this latter generates regular and repeatable flight plans with low battery consumption [24]. As highlighted in Gómez-López et al. [25], the optimal choice of flight parameters has a beneficial effect on the final accuracy results of the photogrammetric process. Indeed, as described in Flores-de-Santiago et al. [26], the attitude of the aircraft at the moment of taking has a significant influence on the efficiency of the structure from motion techniques. The flight path strongly depends on the morphology of the territory to be recovered and it can be structured in a single grid or double grids (in which the grids are arranged perpendicular to each other), based on the scenario complexity [27]. Due to the peculiarities of the on-board sensor, it is common practice to set percentage values of longitudinal and lateral overlap in a range between $70 \%$ and $80 \%$ so as to avoid redundant acquisitions and at the same time optimize photogrammetric elaborations [28].

Multiple acquisitions are programed by differentiating the grip angle: in particular in order to strengthen the altitude differences, it will be necessary to integrate nadiral acquisitions with the tilted cameras convergent towards the point of interest [25]. These additional images reduce problems derived from occlusions and complex geometries.

In the flight altitude setting, in order to avoid distortions and lack of sharpness, it is generally good practice to indicate a cruising speed of the vehicle proportionate to the on-board GNSS receiver frequency and the lens shutter speed. Therefore, it is generally preferred to acquire in hovering mode after a careful calibration of the on-board Inertial Measurement Unit (IMU). Proportionately to the size of the mounted sensor and the configured altitude, an average Ground Sample Distance (GSD) value is derived in accordance with the commissioned specifications [29]. 


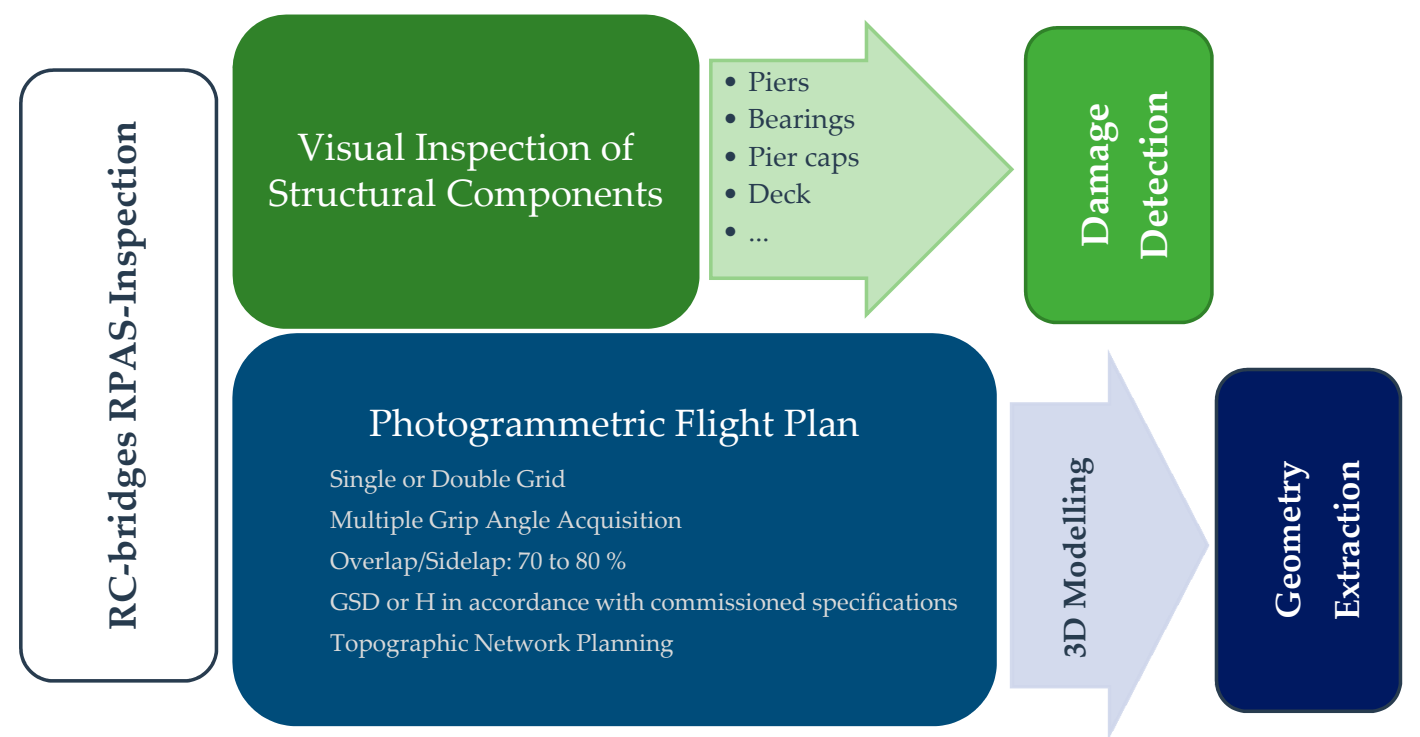

Figure 1. Remotely Piloted Aircraft Systems (RPASs)-based inspection in a simplified schematization. A RPAS investigation of Reinforced Concrete (RC)-bridges was basically divided into visual inspection and photogrammetric operations to provide a measure of the deterioration and geometry of the structure, respectively.

Based on the coverage area of the planned missions, a topographic network materialization is necessary to support the roto-translation, scaling and georeferencing of the model during the orientation phase [29]. In multi-temporal monitoring it is preferable to use non-removable targets, useful to appreciate any discrepancies over time. They can be materialized through artificial targets positioned in the investigated area and easily identifiable also through automatic search techniques in photogrammetric software. Alternatively, it is possible to materialize physical points such as edges, characteristic signs and natural points. Different technical solutions can be adopted to perform this task: in particular, a preliminary distinction can be defined between Total Station and GNSS receiver technologies. The adoption of one less than the other will depend on the accuracy of the commissioned survey.

\subsection{SfM Techniques and $3 D$ Modeling}

The combination of RPAS potentialities for accessing impervious areas with reduced operational time and cost and the improvements of SfM techniques pushed by an exponential computer vision (CV) algorithms development are making photogrammetry more competitive than the traditional survey systems on the small and medium-sized areas [30]. Based on the experiences tested and discussed extensively in the literature and the attempts to validate methodologies for generating products complying with commonly accredited accuracy standards [31,32], an increasing number of scholars keep on proposing progressively sophisticated photogrammetric workflows based on RPAS acquisitions (Figure 2) [33]. A dissertation on a suitable operating methodology for obtaining photogrammetric products useful for the purposes of this work is thus proposed.

As described in Saponaro et al. [34], the main workflow was assumed independent by the adopted software platform and composed of four nodal phases, each of which can be branched out in several steps better suited to the sought final product. 


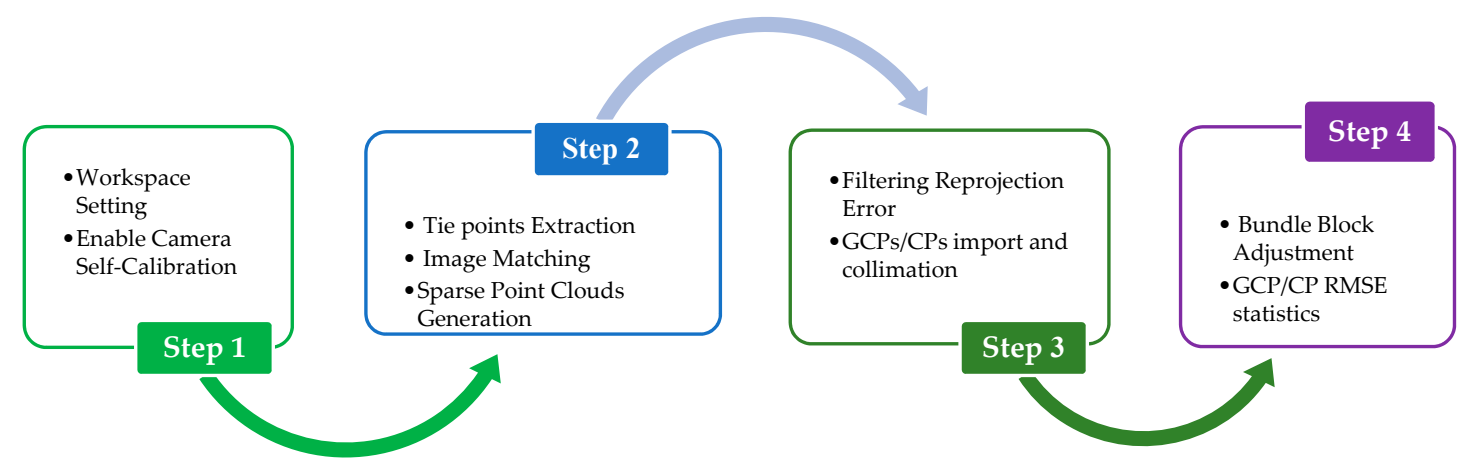

Figure 2. General steps of a photogrammetric process workflow [34]. First step: setting the working environment. Second step: initiating photogrammetric processes using structure from motion techniques. Third step: procedures for refining the obtained models. Fourth step: model verification and validation.

In order to obtain reliable products, a careful and targeted software setup impacts on the plausibility of the performed operations. Avoiding a closing-box processing with default values, Tmušić et al. [35] defines unavoidable to parametrize the software environment with a view to make operations both repeatable and reproducible. The consistency of the interior and exterior orientations and scale of the output models is achievable only establishing a coherence among the input datasets and their weights in photogrammetric equations [34]. A methodology for the calibration of the parameters synthesizing a camera model must be adopted in order to optimize the estimates of interior orientations, one of the main sources of multitude distortions propagation in the final accuracy values [36]. The methodology can follow rigorous operations in the laboratory or be obtained through self-calibration on the acquired data, with the latter often preferred due to the skill to compute reliable values in negligible time compared to the former. A no-metric camera calibration cannot actually be considered stable due to optical-mechanical deterioration and temperature variations and must be corrected during the processing steps, optimizing iteratively the interior orientation.

Based on the primitive Scale Invariant Feature Transform (SIFT) algorithms [37], a multitude of algorithms for searching and counting tie points in the images have been developed and continuously updated. Starting from this archive, the employed software builds the geometric relationships matching all the homologous points among the images. Assisted by any geo-tags registered at the time of shooting, the following steps extract a sparse point cloud, a primitive three-dimensional model but essential for subsequent processing.

The sparse points can be manipulated and filtered, removing all those characterized by rough Reprojection Errors (RE). This latter identifies the difference between the estimated values of the generated point cloud and the same points but re-projected in the images [38]. The software thus learns the adjustments and refines the interior and exterior orientations of each image.

In applications such as mechanical modeling of civil structures (i.e., bridges and viaducts), the metric information possessed by the point cloud is essential for subsequent structural analyses $[12,17,23]$. Several works in the literature show that achieving information that reaches at least the order of a centimetre is possible only by using Indirect Georeferencing (IG) operations, i.e., assuming a number of Ground Control Points (GCPs) greater than 5 and a number of Independent Check Points (ICPs) equal to or less than the former number [39-41]. On the software side, the collimation phase is the most complex and time-consuming step having to mark GCPs and ICPs in all the images where they are visible. Saponaro et al. [42] analyzed a georeferencing mode by optimizing the number and distribution of GCPs in order to reduce both field acquisition and processing time, ensuring the same final accuracy.

Using the Bundle Block Adjustment (BBA) algorithms the model geometry is again refined by minimizing squared REs [43]. Most software also allows heterogeneous information to be aggregated to BBA compensations, such as the position information recorded in each image by the RPAS receiver. 
This information, although less accurate than ground truth, is essential in cases of Direct Georeferencing (DG) and IG with less than 3 GCPs implemented [40].

The validation of the computed products defines the limits of accuracy within which they can be used for the extraction of metric information. The Root Mean Squared Error (RMSE) values, usually ascertained as measure of the accuracy of the entire model, are cumulative values of systematic errors and variances of each point [34]. The same check values are screened on the GCPs, accrediting any robustness and consistency of the georeferencing steps in the photogrammetric blocks.

A sparse cloud of points, although qualified by an orientation, scale and geometry conforms to the reality, is most often unrepresentative due to its low point density [10]. In cases where the aim is to obtain the most suitable geometry possible, a dense point cloud is computed obtaining an average space between points generally less of $1 / 40$ of the previous one.

\subsection{Component Recognition and Geometry Extraction}

The achievement of a 3D point cloud model leads to various applications in the context of the management of civil structures. As an example, in addition to the visual inspection carried out in the field, by analyzing the RPAS-based imagery of the obtained dense point cloud (eventually processed in the textured mesh), it is possible to recognize and collect the degradation phenomena affecting the different structural components even in a virtual environment. Moreover, by means of segmentation of points or classification of the structural components recognized in RPAS imagery, it is possible to achieve metric and material information which are essential for addressing analytical structural assessment as proposed in this work.

These applications induce strong innovations in the processes of management, maintenance and decommissioning of civil works. In this regard, the interest of the various industrial sectors in obtaining intelligent mockups of complex civil structures suitable to being navigated and digitally inspected is constantly growing [44]. On the other hand, the archiving of huge amounts of data, which could be easily interrogable and interpretable, brings the census operations to an advanced state of control aimed at an effective management of the entire portfolio of structures. The digital model does not only act as a virtual representation but turns out to be a container of different type of information (e.g., geometry, constructive methodology, mechanical aspects) about all the components of the construction (structural and non-structural components, facilities, etc.) and the global structure itself (e.g., maintenance scheduling, remaining service life or even structural vulnerability) thus ensuring interoperability between the various actors in the structure lifetime [45]. In this regard, the Building Information Modelling (BIM) concept combines and links the acquired and processed data for a rational management of the entire life cycle of any civil works.

The geometric modelling of the structure is essential within a BIM approach. Once the dense point cloud is achieved, the extraction phase of the geometries can follow an automatic or semi-automatic modelling through Scan to BIM algorithms or through manual tracing operations from the cloud itself [46]. After these operations it is possible to dismember the entire structure in its components characterized by polygons, defined as BIM objects namely multi-layer containers. Automated or semi-automated procedures decrease the operating time and speed-up the entire workflow $[47,48]$. Actually, this type of point cloud management is at its infancy and in particular, point cloud segmentation and classification are very active research topics [46,49]. The segmentation is the process of grouping portions of the point cloud into multiple homogeneous regions with similar properties (such as geometric, radiometric, etc.), while the classification involves the definition and assignment of points to specific classes, called labels, according to different criteria. Most of the segmentation algorithms are tailored to work with $2.5 \mathrm{D}$ surface models or in a 3D space. Often an alternative approach based on a deeply developed 2D-image analysis using machine learning is preferred [49]. In this case, machine learning algorithms allow segmenting the different components of the investigated structure in the 2D-images. Accordingly, the point cloud is classified and portioned with reference to the different 
structural components. Thus, the segmented structural parts are transformed from point clouds into 3D polygons.

The manual tracking of geometries starting from the dense point cloud is instead a primitive methodology but able to establish a feedback relationship between the operator and the used software [46]. The operator thus manually shapes the structural (or non-structural) components starting from the photogrammetric model, not neglecting a large working time spent especially on complicated geometries or when a large number of structures should be modelled. In the particular context of bridge inspections, although the manual approach is expensive in terms of time and modeling efforts, the expert contribution of the operator allows recognizing and categorizing particular structural members such as bearing devices, joints and shear keys which are essential to address further mechanic-based structural analysis. Note that, this is possible only if an exhaustive and detailed data collection on the constructive components part of the deck-substructure connection is performed. This task is deemed to be challenging particularly within the context of existing bridge inspections where these critical components assume wide variety in typology and constructive techniques increasing the difficulties in the "training" process of machine learning algorithms. Currently, although literature works are aimed at classification of components such as deck and piers [49], to the author's best knowledge, no literature applications investigate the automatic characterization of other small but likewise critical structural components such as bearing devices within bridge survey applications.

Finally, once the complex architecture of the structure is reproduced in BIM environment and a georeferenced system to which anchor it is defined, it is possible to integrate and update disaggregated and heterogeneous information for each extracted geometric block (Figure 3). The information collected in the BIM model are the input for the further structural assessment processes which can be performed with conventional FEM approach or simplified methodologies such as the simplified analysis approach described in the following section.

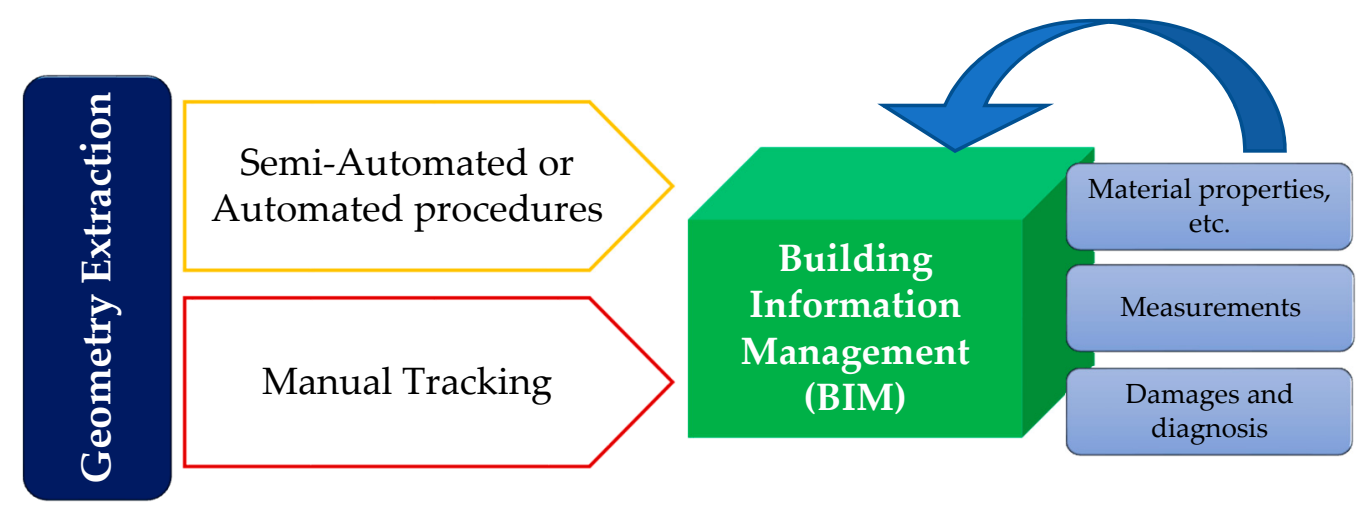

Figure 3. Modeling of a structure in a Building Information Model (BIM) environment and collection of disaggregated and heterogeneous information using manual or semi-automated techniques based on extracted geometries.

\section{Simplified Seismic Risk Assessment}

A simplified procedure for the seismic risk assessment to improve the feasibility of risk-based prioritization strategy is proposed. It is based on data easily attainable by means of a RPAS-based inspection and appropriately arranged within a BIM environment. It is evident that the 3D dense point cloud model reports only geometric and constructive information that are visible by the RGB sensors, while "hidden" constructive details, such as the amount of reinforcements in the different structural members, remain unknown. These data, together with the mechanical properties of the materials, could be retrieved by means of destructive tests on the critical structural members. However, destructive tests require an appropriate preparatory phase aimed at planning the test type and identifying the significant components to be checked. Most times, this complex process is not compatible with the concept of quick and simplified structural assessment to analyze bridge portfolios. 
Since such types of data are necessary to perform a mechanic-based seismic assessment, the first step of the procedure is aimed to a data completion. This task is carried out by hypothesizing the design classes of the materials (unless it is not indicated in any available design documents) and performing a simulated design consistently with the reference (old) design code. The uncertainties on the choice of the design materials are accounted for by representing the investigated bridge by means of several index-bridges having different values of the design properties. Thus, each index-bridge is analyzed according to a simplified mechanic-based approach herein described. This methodology is adapted for simply supported girder RC bridges that is the most spread typology in the Italian context. The simplified procedure herein described to perform the seismic assessment of each index-bridge is based on the assumptions of the Individual Pier Model (IPM) described in [50,51]. This approach can be used for the seismic performance analysis of simply supported deck bridges with independent adjacent decks which represent the most spread typology of Italian existing bridges built during the 1960s-1990s. For the analysis of other bridge typologies such as continuous deck bridges, the simplified procedure reported in [52] can be easily integrated in this workflow. The main steps of the procedure are described below and in Figure 4.

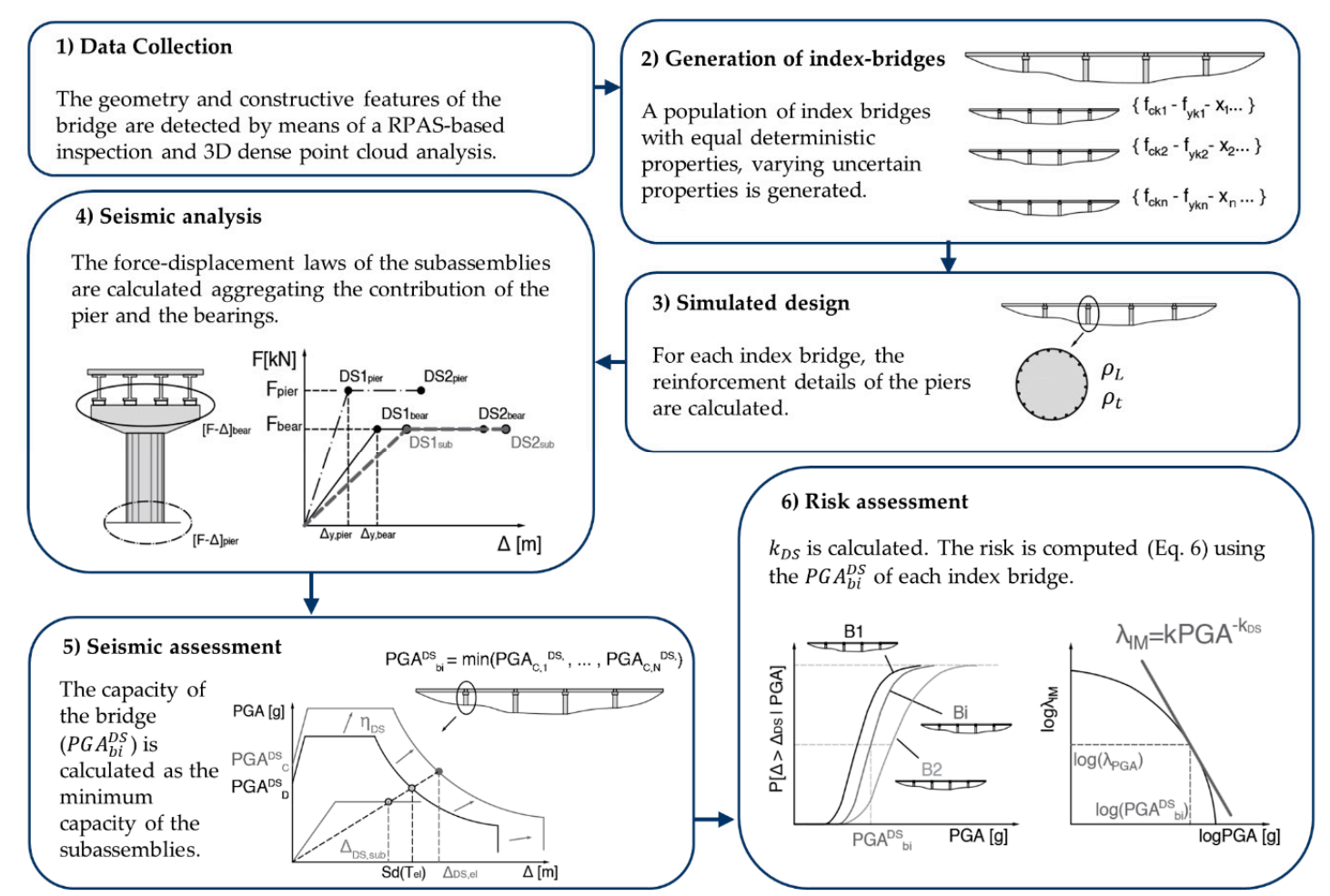

Figure 4. Flowchart of the proposed procedure for the seismic risk assessment of RC bridges.

\subsection{Generation of Index Bridges}

Conventionally, seismic assessment approaches which must deal with the modeling of the epistemic (knowledge-based) uncertainties begin with the generation of index-models [53,54]. The main structure is represented by more than one models which exhibit the same "deterministic" features, varying the uncertain parameters. Statistical distributions, if available, are usually used to model uncertain parameters. At the state of the art and to the author's best knowledge, statistical distributions on design materials for existing bridges are not available, thus uniform (discrete) distributions are chosen in this case (expressing the maximum uncertainty). The same process can be carried out to model other uncertainties linked to unknown mechanical or constructive properties that cannot be detected in the inspection phase. If only discrete uniform distributions are selected, the total amount of index-bridges $\left(N_{\text {indbr }}\right)$ can be calculated with Equation (1) where $n$ is the number of uncertain 
variables and $m_{i}$ is the number of discrete values of the $i$-th variable. If different statistical distributions are used, Monte Carlo simulations or other statistical sampling techniques should be used. Further recommendations to perform this task are proposed in the case study section.

$$
N_{\text {indbr }}=\prod_{i=1}^{n} m_{i}
$$

\subsection{Simulated Design}

Generally, only the substructure members are considered in the simplified seismic analysis of isostatic simply-supported girder bridges, assuming a rigid behavior of the independent adjacent decks. A rigid behavior is also associated to the foundations. For this reason, in the proposed procedure the simulated design is aimed to characterize a likely amount of reinforcements in the piers. The design traffic and seismic loads should be identified according to reference old codes. According to the prescriptions of the reference code, these loads should be appropriately combined to determine the design stresses (pairs of axial stress and flexural moment calculated in both transverse and longitudinal direction) at the base of the piers. These data can be used to estimate the minimum amount of longitudinal reinforcements to ensure that the design stresses are inferior than the axial load and moment capacity. The same process is performed, using the design shear stress in the considered pier, to calculate the transverse reinforcements. It is worth mentioning that the amount of longitudinal and transverse reinforcements should respect the minimum limits that were usually proposed in the codes.

\subsection{Simplified Seismic Analysis}

The seismic behavior of the piers or of the components of the deck-substructure connections are expressed by force-displacement (F-D) laws. For the piers, these are usually calculated by means of simplified formulations applied on the bilinear moment curvature relationship of the base section $[55,56]$. It is worth highlighting that an appropriate geometric characterization of the pier cross section, of the pier cap and of the deck cross section is required to complete this task. These can be easily and accurately measured based on the BIM objects with the methodology proposed in Section 2.3. The exported measurements inherit the accuracy limits from the photogrammetric methodology (Section 2.2). The F-D relations of the piers are calculated with the formulations proposed in [57]. With reference to the bearing typology, the mechanical behavior of the bearing devices, which compose the deck-pier (-abutment) connections should be also retrieved. Appropriate indications to model the response of different types of bearing devices, together with shear keys and abutment-backfill systems are reported in [58].

Once the F-D relations are calculated for all the components, these should be aggregated to characterize the mechanic response of each deck-pier (-abutment) subassembly. This process is graphically shown in Figure 4 (step 4). Each subassembly is, thus, represented by an equivalent SDoF system in which the piers (or abutments) and the corresponding deck-connection system work as a series system. An effective mass of the equivalent subassembly is calculated summing up the mass contribution of the tributary seismic deck mass, the mass of the pier cap and a third of the mass of the pier [59].

The performance of each subassembly under a given seismic demand can be categorized with reference to appropriate displacement-based damage state (DS) thresholds which determine the reaching of a given limit state of the subassembly. To this aim, appropriate DS thresholds should be identified for the different components and converted in terms of displacement of the corresponding subassembly.

\subsection{Seismic Assessment and Fragility Curves}

Once all the subassemblies of the bridge are analyzed, the performance of the bridge under a given seismic action can be calculated. To this aim, the seismic demand with reference to the location of the bridge, expressed by elastic response spectra, should be retrieved. The spectral demand should be 
calculated according to the investigated limit states and the corresponding exceedance return periods retrieved by the reference code.

If the response of the bridge in transverse direction is investigated, the performance of each subassembly should be computed separately, according to the IPM approach. This latter can be applied in most of the existing bridges where fixed or rubber bearings ensure the transmission of shear forces between the deck and the substructure members in transverse directions, while allowing relative rotations between the adjacent decks. On the other hand, in the longitudinal direction, the structural scheme composed by the different subassemblies should be appropriately defined. If the gap size between adjacent decks is seismically designed and allow the relative displacement between the subassemblies, the IPM approach can be applied also in this case. On the contrary, if the gap size is limited (designed considering thermal deformations only) or if shock-transmitters are present, the capacity curves of the subassemblies should be appropriately aggregated, working as a parallel system [50,60]. In this case, a rigid axial behavior of the deck is assumed. In this case, the response of the bridge is defined with a single force-displacement law. Global displacement-based DS thresholds should be allocated on the global capacity curve with reference to the DS thresholds of the weakest component (the first that reaches the damage state).

In the proposed procedure, the displacement-based assessment algorithm described in [57] for SDoF systems is applied to calculate the seismic performance of the bridge. If the IPM approach is applied, a spectral reduction factor $\eta_{D S}$ is associated to each displacement-based DS threshold. It is used to convert the inelastic displacement capacity of the subassembly in an equivalent elastic one and is calculated with Equation (2). $\xi_{D S}$ is the equivalent viscous damping parameter of the subassembly and is computed aggregating the effective damping $\left(\xi_{D S, i}\right)$ of the different components (e.g., pier, bearing devices) and the corresponding displacements by means of Equation (3). $\Delta_{D S, i}$ is the damage state displacement of the $i$-th component and and $\Delta_{D S, \text { sub }}$ is the damage state threshold (top displacement) of the subassembly. $C_{e v d, i}$ depends on the cyclic response of the specific component and is equal to 0.444 for piers and 0.565 for rubber bearings; $\mu_{D S, i}$ is the component ductility capacity at the considered damage state.

$$
\begin{gathered}
\eta_{D S}=\sqrt{0.07 /\left(0.02+\xi_{D S}\right)} \\
\xi_{D S}=\frac{\sum_{i=1}^{N} \Delta_{D S, i} \xi_{D S, i}}{\Delta_{D S, s u b}}, \text { where } \xi_{D S, i}=0.05+C_{e v d, i}\left(\mu_{D S, i}-1 / \pi \mu_{D S, i}\right)
\end{gathered}
$$

The equivalent elastic displacement capacity $\Delta_{D S, e l}$ is computed by dividing the displacement capacity at a given DS $\left(\Delta_{D S, \text { sub }}\right)$ for the corresponding $\eta_{D S}$ and is compared to the spectral displacement demands $S d\left(T_{D S}\right)$ where $T_{D S}$ is the effective period of the subassembly at a given DS. The capacity of each subassembly is expressed by a capacity peak ground acceleration $\left(P G A_{c}^{D S}\right)$ calculated with Equation (4), where $P G A_{D}^{D S}$ is the PGA of the code elastic demand at the investigated damage state. This procedure is graphically represented in Figure 4 (step 5) where the capacity curve and the spectral demand are reported in an acceleration-displacement plane. This process is repeated for all the subassembly.

$$
P G A_{C}^{D S}=\Delta_{D S, e l} / S d\left(T_{D S}\right) \cdot P G A_{D}^{D S}
$$

According to the IPM fundamentals, the minimum value of the PGA-based capacity of the different subassemblies at a given DS represents the capacity of the bridge $\left(P G A_{b r i d g e}^{D S}\right)$. If a single capacity curve is associated to the response of the bridge (in longitudinal direction), the $P G A_{\text {bridge }}^{D S}$ can be directly determined, since, for each damage state, the critical member is known. The $\eta_{D S}$ and $T_{D S}$ are calculated for the bridge aggregating the masses and the equivalent viscous damping factors of the different subassemblies. The value of $P G A_{\text {bridge }}^{D S}$ is used to represent the median value of the fragility curve expressed by a lognormal cumulative probability density function. It expresses the probability to reach or exceed a given damage state conditioned to a given value of intensity measure indicated as $P\left(\Delta \geq \Delta_{D S} \mid P G A\right)$ in Figure 4 (step 6). The logarithmic standard deviation (or simply dispersion) 
can be calculated analytically. However, consistently with the simplicity of the proposed algorithm, literature values can be used as proposed in [61].

At this point, the fragility curves for all the damage states are associated to the index bridges. The probability of reaching or exceeding a damage state of the main bridge can expressed by the range of the maximum and minimum ordinates of the fragility curve populations of the index bridges at a given seismic intensity.

\subsection{Simplified Risk Assessment}

The output of the procedure is a quantification of the risk expressed by the mean annual frequency of exceeding a given limit state $\left(\lambda_{D S}\right)$. Generally, to perform the risk assessment, the first part of Equation (5) should be solved. To this aim, hazard curves $\left(\lambda_{I M}(P G A)\right)$ related to the location of the investigated bridge are needed, representing the annual rate of exceedance of a given seismic intensity (which in this work is the PGA). An example of hazard curve is shown in Figure 4 (step 6) where $\lambda_{I M}(P G A)$ and $P G A$ are represented in a log-log plane. The hazard curves can be obtained by appropriate probabilistic seismic hazard analysis or retrieved from the seismic demand parameters provided by the regulatory codes. The proposed procedure resorts to the simplified closed-form solutions proposed by Cornell [62] expressed in the second part of Equation (5) in which $\beta_{D S}$ is the logarithmic standard deviation of the fragility and $k_{D S}$ is the hazard curve slope calculated at $P G A_{\text {bridge }}^{D S}$ in logarithmic scale.

$$
\lambda_{D S, \text { bridge }}=\int_{0}^{+\infty} P(D S \mid \mathrm{PGA}) \cdot\left|d \lambda_{I M}(P G A)\right| \cong \lambda_{I M}\left(P G A_{\text {bridge }}^{D S}\right) e^{\frac{1}{2} \beta_{D S}^{2} k_{D S}^{2}}
$$

In the proposed procedure, the $\lambda_{D S \text {,bridge }}$ is calculated for each index bridges. In this way, the risk of the main bridge can be expressed as the average of the risk calculated for each index bridges at a given DS. The range of $\left[\min \left(\lambda_{D S, \text { bridge }}\right), \max \left(\lambda_{D S, \text { bridge }}\right)\right]$ shows the variability in risk linked to the lack of knowledge (i.e., epistemic uncertainty) of the system.

\section{Case Study}

The considered case study is a RC-bridge part of the provincial road network of the Basilicata geographical region (Southern Italy). It is located in Grottole, a town $25 \mathrm{~km}$ from Matera. The bridge overpasses a natural erosive furrow adjacent to the lake of San Giuliano (Figure 5). The bridge was designed in the period between 1980-1984, when the area was classified with low-seismicity (Zone 3) according to the seismic design regulatory code of the period [63]. With the development of the Italian seismic regulatory framework, the location of the bridge is currently classified as a medium level seismic hazard zone, with an expected Peak Ground Acceleration (10\% exceedance probability in 50 years) of $0.15 \mathrm{~g}$.

The bridge exhibits five $30 \mathrm{~m}$-long spans. The longitudinal structural scheme is composed by simply-supported independent adjacent decks consisting of four precast RC girders having a I-shaped cross section and height equal to of $1.7 \mathrm{~m}$. The deck-substructure connection system is composed by two lines of four neoprene pads which are typical of the Italian bridges designed in the 1950s-1990s. Seat-type abutments are present as many of the bridges of the context. The piers exhibit a circular cross-section single-column whose heights range between 6.6 and $13.6 \mathrm{~m}$. Two-meter high RC pier caps that distribute the permanent and traffic loads deriving from the deck to the piers are placed at the top of the piers. Four transverse beams per span are distributed along the span length to transfer the traffic loads between the different girders. 


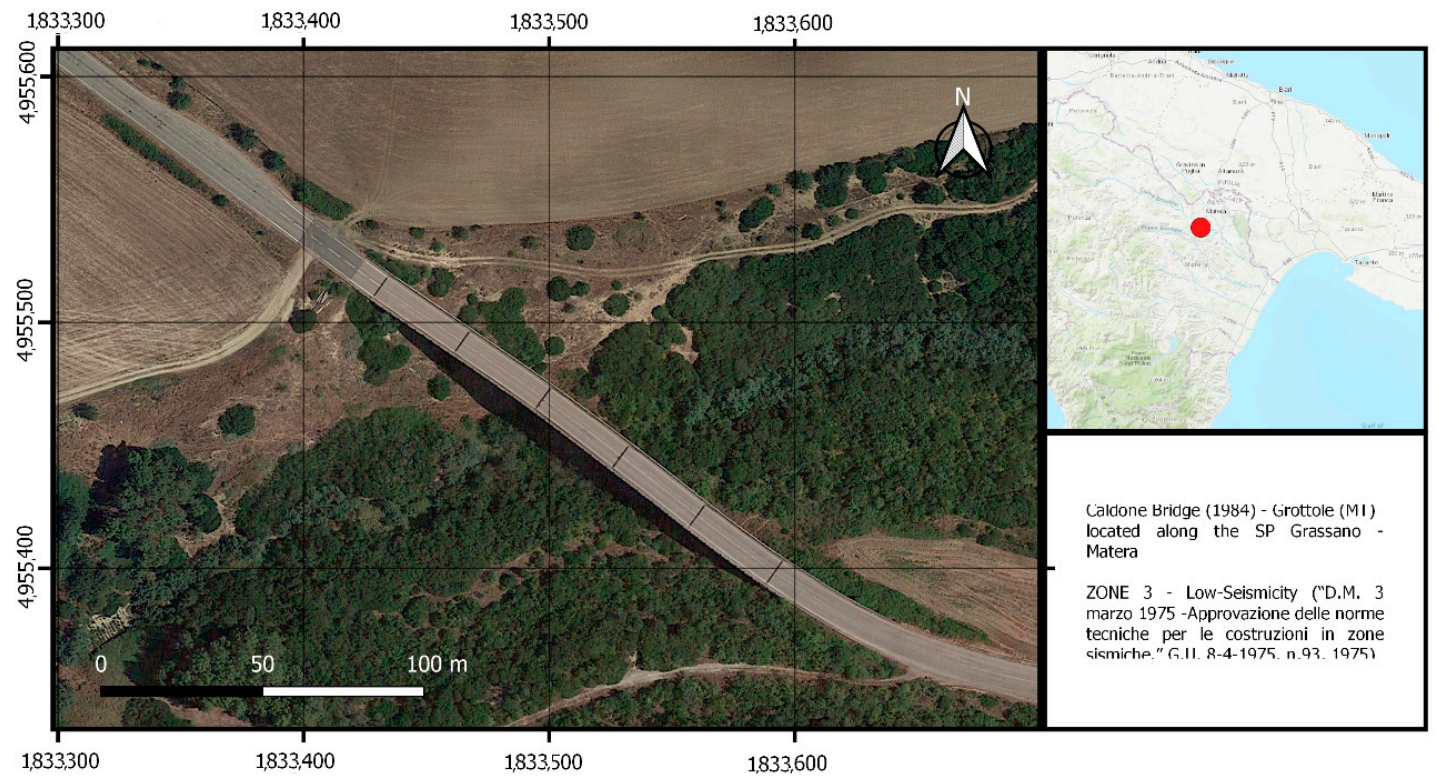

Figure 5. Location of the study area (Google Maps (C) 2020-Maxar Technologies).

\subsection{Data Acquisition}

Using a lightweight RPAS quadcopter, namely a DJI (Dà-Jiāng Innovations, Shenzhen, China) Mavic 2 Zoom of about $905 \mathrm{~g}$, equipped with a $20 \mathrm{MP}$ camera (1-inch CMOS sensor, IFOV equal to $77^{\circ}$ ) with a focal length varying from $24-48 \mathrm{~mm}$ but set at $24 \mathrm{~mm}$, two flights at $30 \mathrm{~m}$ Above Ground Level (AGL) were planned on 26 September 2019. The first flight (FL-1) was planned setting a nadiral view of the camera, the second one (FL-2), instead, with $45^{\circ}$ oblique-camera in front of each side of the deck. A longitudinal overlap and sidelap rate of $80 \%$ were set for the first mission, while $75 \%$ for the second. A dataset of 97 images along the main axis of the bridge were collected for the acquisition FL-1 in 5 min and 49 s, 190 symmetrical images in FL-2 in 13 min and $48 \mathrm{~s}$, both with an average Ground Sampling Distance (GSD) of $1.68 \mathrm{~cm} /$ pixel. Table 1 summarizes the characteristics of the two planned acquisitions.

Table 1. Main features of the performed flight missions.

\begin{tabular}{cccccc}
\hline Flight & $\begin{array}{c}\text { Altitude } \\
(\mathbf{m})\end{array}$ & $\begin{array}{c}\text { GSD } \\
(\mathbf{c m} / \text { pixel) }\end{array}$ & $\begin{array}{c}\text { Inclination } \\
\text { Camera }\left(^{\circ}\right)\end{array}$ & Overlap/Sidelap & Time \\
\hline FL-1 & 30 & 1.68 & $90^{\circ}$ & $80 / 80 \%$ & 5 min $49 \mathrm{~s}$ \\
FL-2 & 30 & 1.68 & $45^{\circ}$ & $75 / 75 \%$ & 13 min $48 \mathrm{~s}$ \\
\hline
\end{tabular}

Eleven targets were materialized with a homogeneous distribution in the study area, paying attention to the large differences in height between the targets on pier bases and on the road surface. Nine of these latter were considered as GCPs for the georeferencing phase, while the remaining points were fixed as ICPs for the accuracy validation. They were placed at the joints between the independent adjacent decks of the viaduct, varying the side for each span. A target was placed at the base of the central pier, while the two ICPs were measured in the middle of the roadway. Afterwards, the targets were measured in network nRTK mode with a Leica Geosystem (Leica Geosystem AG part of Hexagon AB group, Canton St. Gallen, Switzerland) GS08 Plus receiver in a WGS84/UTM zone 33N (EPSG:32633) Reference System, connected to the local permanent station of the National Dynamic Network (RDN2008) of the Continuously Operating Reference Stations (CORS). The achieved measurements reached an acceptable regular accuracy along the three axes X, Y and Z of about 2 $\mathrm{cm}$, an intrinsic value derived from the limits of this measurement technique. Subsequently, it was necessary to act on the altimetric component, converting them from ellipsoidal to orthometric altitude using the open source Italian software ConveRgo (Conversioni di coordinate per le Regioni). Once 
the photogrammetric acquisitions were completed, a close visual inspection was carried out using a DJI (Dà-Jiāng Innovations, Shenzhen, China) Phantom 4 Pro quadcopter (20 MP RGB-sensor, 1-inch CMOS sensor, IFOV equal to $84^{\circ}$, focal length equal to $24 \mathrm{~mm}$ ) for manual acquisition of the state of degradation of the infrastructure (Figure 6). The acquired images represent additional information for structural risk and deterioration assessment.

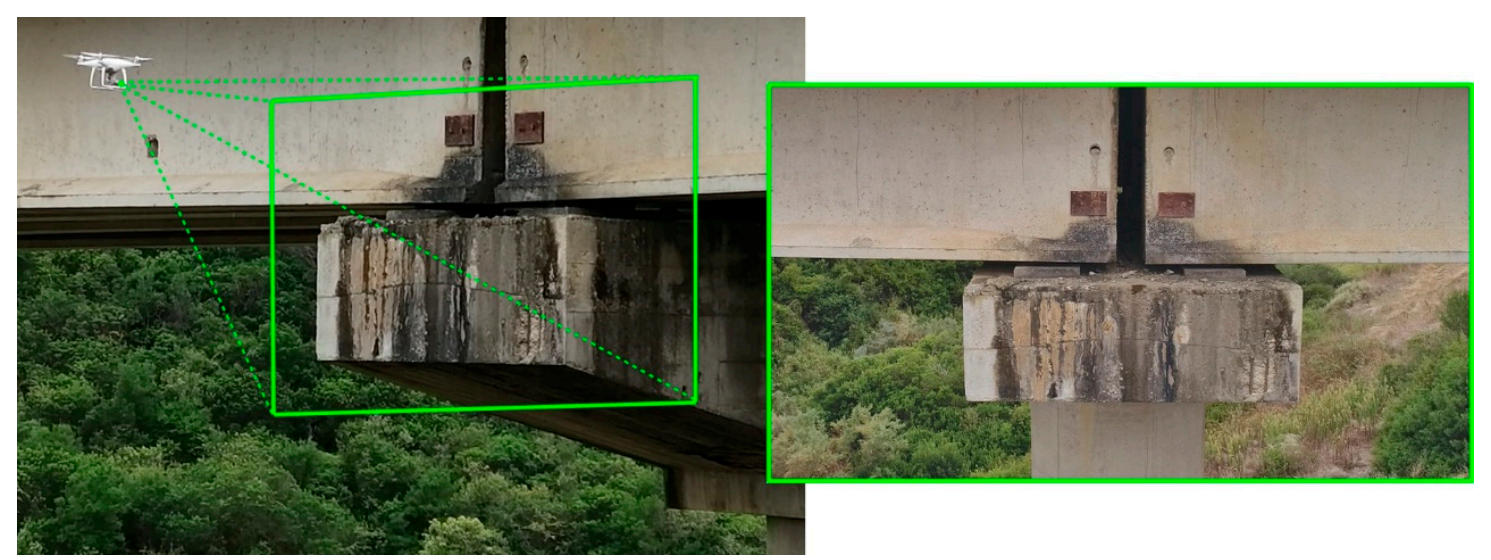

Figure 6. Visual inspection of the side of the structure by RPAS in manual mode.

\subsection{RPAS Data Processing}

Taking note of the prerogatives described in paragraph 2.2, Agisoft Metashape (v.1.5.4.8885) was preferred as a software platform for carrying out photogrammetric operations on the acquired datasets. The latter represents a software application widely used in the academic and professional field for the robustness of the obtained results.

The software working environment has been governed by an adequate parameterization as described below. The Settings panel shows three areas of configuration, in particular: the Reference Settings act on the general coordinate system, being able to indicate the WGS84/UTM zone 33N (EPSG::32633) system, chosen as reference; the other two configuration areas parameterize on one hand the accuracy of the measurements in the field, on the other they allow assigning a weight to the measurements in the software workspace. First, the accuracy of the on-board RPAS receiver, the Inertial Measurement Unit (IMU), and the accuracy of the GCP coordinates in meters when acquired are defined. A value of $3 \mathrm{~m}$ was set in the Camera Accuracy (m) option, kept at 10 degrees in the Camera Accuracy (deg) option (because the RPAS does not have factory specifications for IMU sensitivity), and $0.02 \mathrm{~m}$ in the Marker Accuracy $(\mathrm{m})$ parameter. In the Image Coordinates Accuracy option, the Marker Accuracy (pix) of 0.5 was assigned, i.e., the accuracy of the user in collimating the markers in the software workspace. The Tie Point Accuracy option of 3 pixels, on the other hand, identifies the weight given to the tying points when adjusting the blocks. In Camera Calibration, camera parameter self-corrections, initially extracted from the metadata of each image, were enabled in each bundle adjustment. The last obtained parameters were thus validated verifying the standard deviation error for each one in the Correlation tab in the Distortion Plot panel [64].

In the next step, the alignment process of the cameras was started with Align Cameras, in High quality and enabling the automatic pre-filter with the values 40,000 and 4000 in the Key Point and Tie Point Limits options, respectively.

The process required $3 \mathrm{~min}$ and $15 \mathrm{~s}$ of processing time in the matching phase and $2 \mathrm{~min}$ and $8 \mathrm{~s}$ in the image alignment. At the end of the processing, a sparse cloud of 275,687 points was returned, with an average Reprojection Error (RE) of 0.744 pixels and an average point spacing of approximately 23 points $/ \mathrm{m}^{2}$.

The obtained point cloud underwent a finishing manipulation as described in Section 2.2. Gradual Selection option contains different filtering tools for sparse point clouds. Following the proposals discussed in Saponaro et al. [40], three filtering operations were carried out: first of all the Uncertainty 
Reconstruction was evaluated with a value equal to 10; then the option Projection Accuracy was selected with a value equal to 3; finally with Reprojection Error all those points above the threshold equal to 0.40 were selected. In each step, the points selected by the filter were removed and the entire block adapted to an update of the estimated orientations. At the end of the filtering process, the BBA was started using the Optimize Cameras command.

The filtered cloud of 59,086 points then had a RE of 0.373 pixels so that it could be considered consistent and robust for further processing.

Later the coordinates of the 11 GCPs and ICPs were imported into the working environment (Figure 7). Once the markers were filled, image by image, trying to keep low their reprojection value in the model, the BBA procedures were started again by deselecting from the Reference panel the input of the camera positional information. At the end of the process, the average error and RMSE values of the selected GCPs and ICPs were recorded in the same panel, as reported in the Table 2.

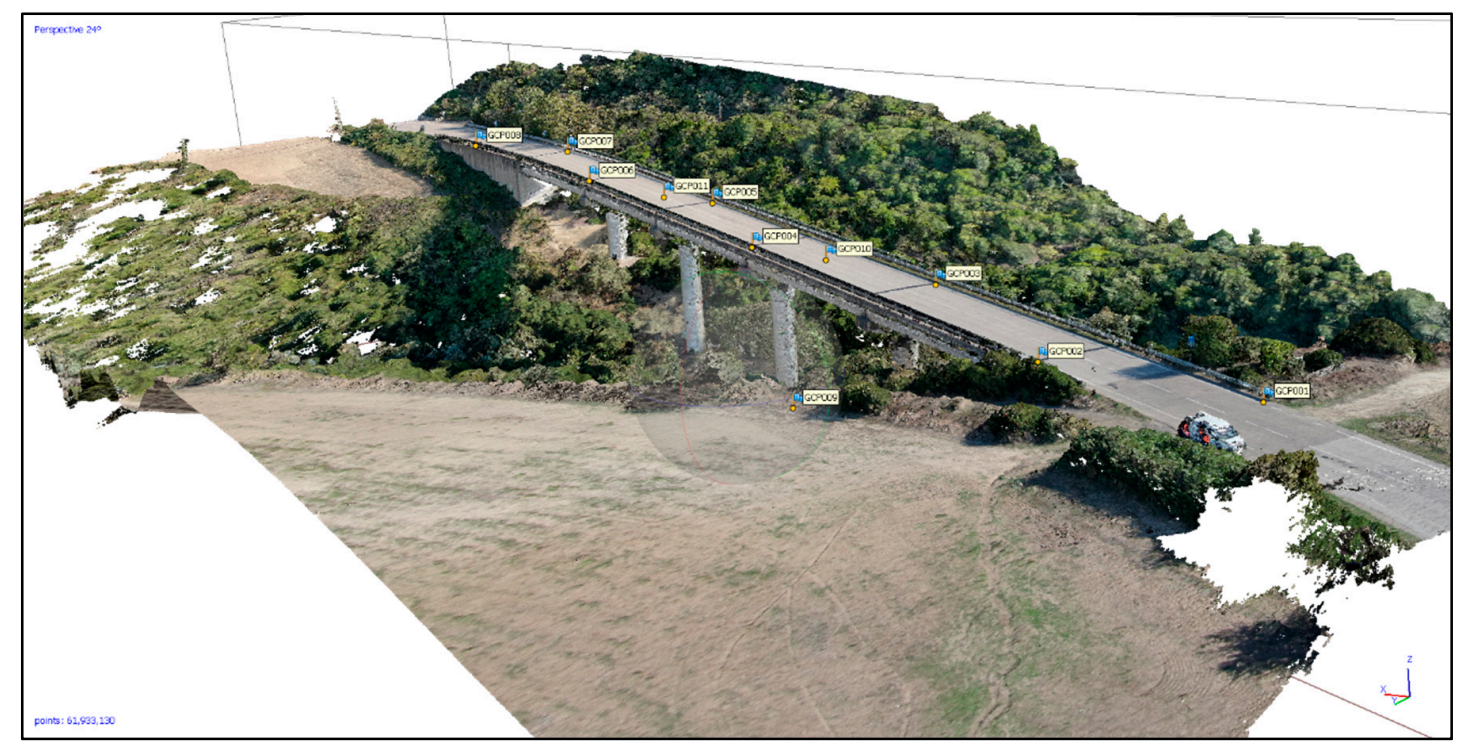

Figure 7. View of the obtained dense point cloud and GCPs/ICPs placement along the structure.

Table 2. Final Accuracies recorded in Ground Control Points (GCPs) and Independent Check Points (ICPs) expressed in terms of Root Mean Squared Error (RMSE) and Reprojection Errors (RE).

\begin{tabular}{cccccc}
\hline ID & RMSE $_{\mathbf{X}}(\mathbf{m})$ & RMSE $_{\mathbf{Y}}(\mathbf{m})$ & RMSE $_{\mathbf{Z}}(\mathbf{m})$ & RMSE $_{\mathbf{X Y}} \mathbf{Z}(\mathbf{m})$ & $\mathbf{R E}($ Pixel) \\
\hline GCPS & 0.016 & 0.015 & 0.013 & 0.026 & 0.303 \\
ICPS & 0.015 & 0.014 & 0.004 & 0.021 & 0.306 \\
\hline
\end{tabular}

At the end of the processing chain, the Dense Matching algorithms were started in order to obtain, in High quality and filtered in Mild mode, a dense cloud of 61,933,130 points (Figure 7). The process took $3 \mathrm{~h}$ and $21 \mathrm{~min}$ for a point density of $884 \mathrm{pts} / \mathrm{m}^{2}$. The cloud thus obtained was exported for further processing.

\subsection{Geometry Extraction and Storage}

Once the dense point cloud was obtained, following the workflow described in Section 2, the process of extracting the geometries of the structural components in the BIM environment was started. The entire flow of operations was conducted in the Autodesk Revit 2020 work environment, a commercially licensed software platform widely used in the building industry.

The geometric modeling of the viaduct was carried out resorting to a manual approach, to capture adequately the characteristics of minor size structural components (e.g., neoprene bearings) that are deemed to be essential for the further simplified structural analyses. 
Using the Families libraries defined as Industry Foundation Classes (IFC) classes [65], each structural component has been converted from a portion of point cloud into a solid block. Briefly, for the modeling of each block, the main dimensions were measured and fixed from the dense point clouds and then the most suitable family was selected in the library or created by extrusion using the appropriate editor. An object was thus generated tracing the observable shapes and assigning all the properties connected to it (e.g., materials, mechanical properties). Finally, the positioning of the generated object was performed by anchoring it to an appropriate spatial reference system. Each extracted geometric block became a container for a variety of information. In particular, in addition to the inherit data about the physical properties of the constituent materials of the specific element, different levels of information have been added about visual inspection and damage analysis. Each component was surveyed and structured in the composition of the structure, attaching to it the diagnostic reports drawn up by the operator in the field.

The data retrieved by the BIM objects were organized in an Excel spreadsheet including geometric and constructive details which are necessary to calculate the seismic risk by means of the simplified procedure described in Section 3. The spreadsheet was designed based on previously developed research works aimed at collecting data for regional-scale vulnerability assessment of buildings [66]. A complete list of this data is reported in Figure 8. It is worth noting that a first section includes general information about the design period or the design seismic demand which are useful to perform the simulated design together with the layout of the roadway (e.g., road width, sidewalk width). Note that more than one value of the design class of concrete and steel can be specified to address the generation of model populations to consider the knowledge-based uncertainties.

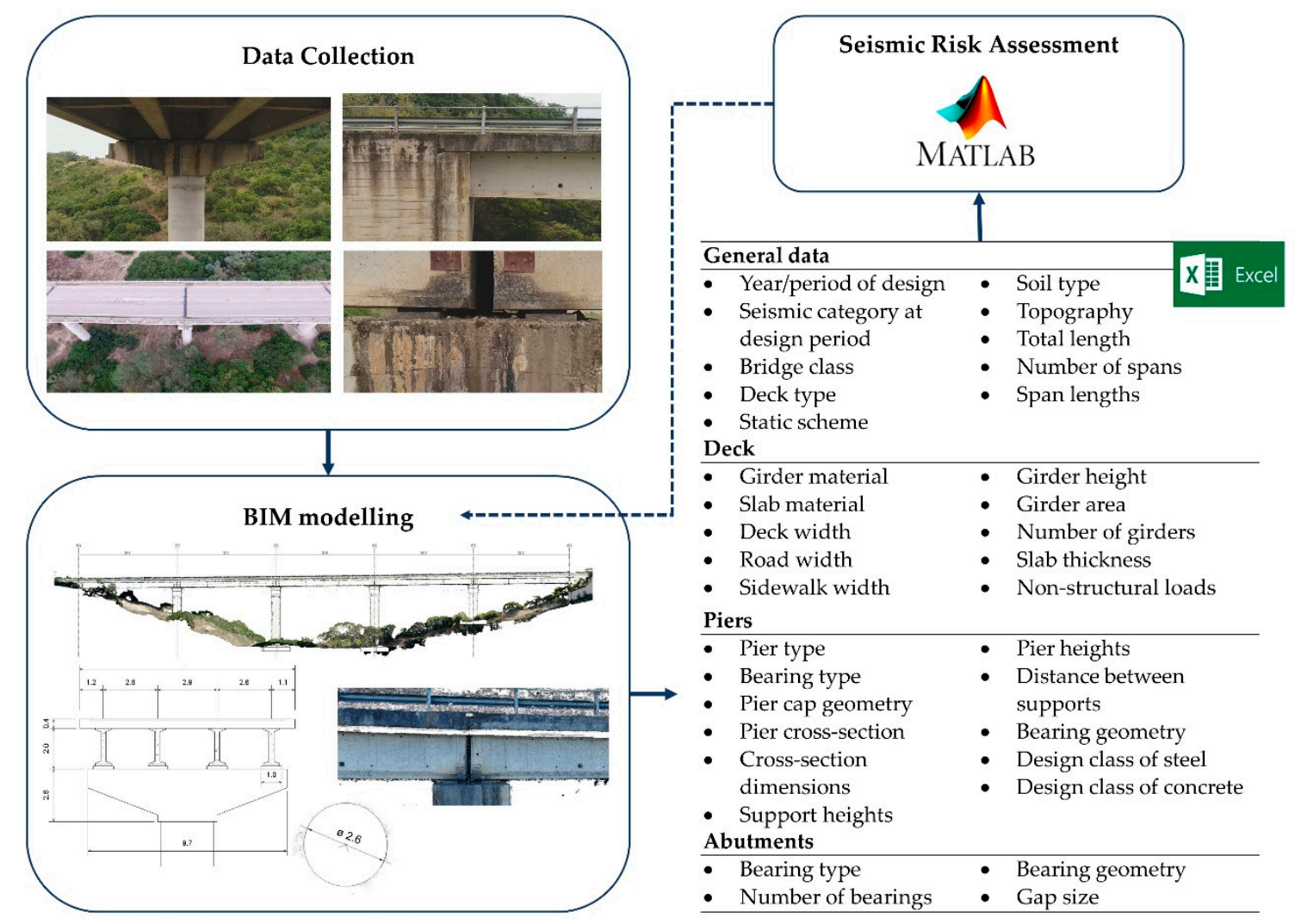

Figure 8. Sequence of steps for the geometry extraction and allocation of data in BIM and Excel spreadsheet to perform the seismic risk assessment. A list of the data necessary for the risk calculation is indicated. 


\subsection{Seismic Risk Calculation}

A MATLAB (version R2018b) [67] routine was designed to import the knowledge data of the bridge and perform the entire seismic risk assessment procedure. First, it carries out the generation of index-bridges, considering the residual uncertainties of the data collection process. Then, the simulated design of each index-bridge is automatically performed, the seismic assessment is carried out and the risk is quantified according to the calculation described in Section 3. In this section, the main steps of the procedure applied to the bridge case study are discussed. Since the aim of this section is to better clarify the application of the procedure by means of the case study, the seismic analysis is performed in transverse direction only.

Since blueprints or design data are not available for the investigated case study, the material design classes and the steel reinforcements are considered as epistemic uncertainties. The design concrete characteristic strength $\left(f_{c k}\right)$ is supposed ranging between 25, 30 and $35 \mathrm{MPa}$. Two values of the characteristic yielding strength of the steel $\left(f_{y k}\right), 375$ and $440 \mathrm{MPa}$, are assumed, representative of the steel type FeB38k and FeB44k which were particularly spread in the design period in Italy.

Firstly, six index-bridges are generated (B1 to B6 in Table 3). and the simulated designed is performed. Note that, in the past common practice, the design of transverse reinforcement in RC columns with large diameter was dictated by constructive rather than mechanical reason. This is because of the adopted shear capacity models which foresees that the shear stresses were almost entirely absorbed by the concrete. For this reason, the volumetric ratio $\left(\rho_{T}\right)$ of the transverse reinforcement is retrieved by literature works that investigate similar bridge typologies in Italy [68]. Each of the previously generated index bridges is modelled with two pre-determined values of $\rho_{T}$. The calculated amount of likely longitudinal reinforcement $\left(\rho_{L}\right)$ together with the assumed value for transverse reinforcement $\left(\rho_{T}\right)$ are reported in Table 3. Design data, reinforcement ratio of the generated index bridges and results of the moment curvature analysis of the pier 1. In addition, the table lists the bilinear moment curvature law of the base section of the shortest pier (P1) calculated with CUMBIA [69], where $\varphi_{Y}$ and $\varphi_{U}$ are the yielding and ultimate curvatures and $M_{Y}$ and $M_{U}$ are the yielding and ultimate moments. It is worth mentioning that the index-bridges having the design concrete strength equal to $25 \mathrm{MPa}$ are deleted from the dataset, because the simulated design yields to values of reinforcements not compatible with the geometry of the piers and the code requirements.

Table 3. Design data, reinforcement ratio of the generated index bridges and results of the moment curvature analysis of the pier 1 .

\begin{tabular}{cccccccccc}
\hline \multicolumn{2}{c}{ Bridge } & $f_{c k}$ & $f_{y k}$ & $\rho_{L}$ & $\rho_{T}$ & $\varphi_{Y}$ & $\varphi_{u}$ & $M_{y}$ & $M_{u}$ \\
\hline B1 & $\mathrm{a}$ & 30 & 380 & 0.63 & 0.09 & 0.0016 & 0.0209 & 24361 & 23906 \\
& $\mathrm{~b}$ & & & & 0.13 & 0.0017 & 0.0233 & 24436 & 23835 \\
B2 & $\mathrm{a}$ & 30 & 440 & 0.81 & 0.09 & 0.0019 & 0.0186 & 31771 & 31268 \\
& $\mathrm{~b}$ & & & & 0.13 & 0.0018 & 0.0265 & 31836 & 31197 \\
B3 & $\mathrm{a}$ & 35 & 380 & 0.31 & 0.09 & 0.0014 & 0.0265 & 16069 & 16333 \\
& $\mathrm{~b}$ & & & & 0.13 & 0.0014 & 0.0305 & 16095 & 15455 \\
B4 & $\mathrm{a}$ & 35 & 440 & 0.37 & 0.09 & 0.0017 & 0.0244 & 19806 & 19429 \\
& $\mathrm{~b}$ & & & & 0.13 & 0.0017 & 0.0272 & 19693 & 19479 \\
B5 & & 25 & 380 & & & & Not compatible & & \\
B6 & 25 & 440 & & & & & \\
\hline
\end{tabular}

The constitutive relations of the piers and deck-substructure connections are calculated in terms of force-displacement laws. Bilinear elastic-plastic laws are defined for the piers, while an elastic-perfectly plastic behavior is associated to neoprene bearings. The applied formulations are shown in Table 4, together with the corresponding equations and the displacement-based damage states thresholds $\left(\Delta_{D S 1}, \Delta_{D S 2}, \Delta_{D S 3}\right)$. These latter are defined consistently with [68] and corresponds to slight, moderate and severe limit state. In the table, $\Delta_{Y}$ and $\Delta_{U}$ are the yielding and ultimate displacements, whereas $F_{Y}$ and $F_{U}$ are the yielding and ultimate shear forces. The formulations proposed in the table consider 
a flexural response of the piers. Preliminary analyses are conducted to exclude shear and buckling phenomena that may limit the ultimate flexure capacity of the piers. The deformative response of the abutment is neglected for the response in transverse direction.

Table 4. Bilinear force-displacement law and damage states for RC piers and neoprene bearings.

\begin{tabular}{|c|c|c|c|c|c|c|c|}
\hline Member Type & $\Delta_{Y}$ & $\Delta_{u}$ & $F_{Y}$ & $F_{U}$ & $\Delta_{D S 1}$ & $\Delta_{D S 2}$ & $\Delta_{D S 3}$ \\
\hline RC pier & $\varphi_{y} H^{2} / 3$ & $\begin{array}{c}\Delta_{y}+ \\
\left(\varphi_{u}-\varphi_{y}\right) L_{p}\left(H+0.5 L_{p}\right)\end{array}$ & $\frac{M_{Y}}{H}$ & $\frac{M_{U}}{H}$ & $\Delta_{Y}$ & $\begin{array}{c}\Delta_{Y}+ \\
\frac{\left(\Delta_{U}-\Delta_{Y}\right)}{2}\end{array}$ & $\Delta_{U}$ \\
\hline $\begin{array}{c}\text { Neoprene } \\
\text { bearing }\end{array}$ & $\Delta_{f r}=\mu_{f r} P / K_{b}$ & $\Delta_{u n s}$ & $F_{f r}=\mu_{f r} P$ & $F_{f r}$ & $\Delta_{f r}$ & $\Delta_{p a d}$ & $\Delta_{u n s}$ \\
\hline
\end{tabular}

$H$ is the height of the equivalent cantilever of the pier, $L_{p}$ is the plastic hinge length [59]; $F_{f r}, \Delta_{f r}$ are the friction shear strength and the corresponding displacement at the slipping between deck and neoprene bearings; $K_{b}$ is the shear stiffness of the neoprene bearing, defined as $G A / t_{b}$ where $G$ is the neoprene shear modulus (assumed as $1 \mathrm{GPa}$ [58]), $\mathrm{A}$ is the cross-section area and $t_{B}$ is the thickness of the neoprene pad; $\mu_{f r}$ is the friction coefficient between concrete and neoprene (usually assumed as 0.4 [58]) and $P$ is the tributary gravity load; $\Delta_{u n s}$ is the displacement at deck unseating, $\Delta_{\text {pad }}$ is the pad dimension in the considered direction.

The force-displacement relations are derived for each member and are aggregated to determine the response of the different subassemblies that compose the single index-bridge. Figure 9a shows the capacity curves of the entire dataset of subassemblies (for all the index bridges) calculated in the transverse direction. In the figure, the F-D laws of the same subassembly (S1, S2, S3 and S4) among the different index bridges are indicated with the same line pattern. The markers indicate the DS thresholds of the subassembly: the squared markers indicate that the bearings determine the damage states, while the circular markers indicate that the piers are the critical element of the subassembly. The behavior of the deck-abutment subassemblies is indicated with the unique red-dashed line assuming no variability among the index-bridges. It is shown that the deck-pier connections determine the reaching of the different damage states for the subassemblies of the shortest piers (S1 and S4). The variation of the longitudinal reinforcement ratio in these piers induces a low variability in the elastic stiffness, with no differences in post-elastic phase. This is because of the slipping of the neoprene bearings which limit an increase of the total subassembly base shear over the shear strength of the deck-pier connection. On the contrary, in B1, B3 and B4 the tallest piers (S2 and S3) exhibit a lower shear strength with respect to the shear strength of the deck-pier connection system, reaching first the damage state. In the case of B2, the strength of the central piers enhances with the increase of the amount of longitudinal reinforcement and the bearings reach their maximum strength preventing the damage of the piers. The F-D laws of the bridges with the highest amount of reinforcements (B1b, B2b, B3b, B4b) are not shown since these are extremely similar to the F-D laws shown in Figure 9a, although an increasing amount of transverse reinforcement postpones the displacement thresholds for DS2 and DS3. This is proved by the moment curvature laws reported in Table 3. 

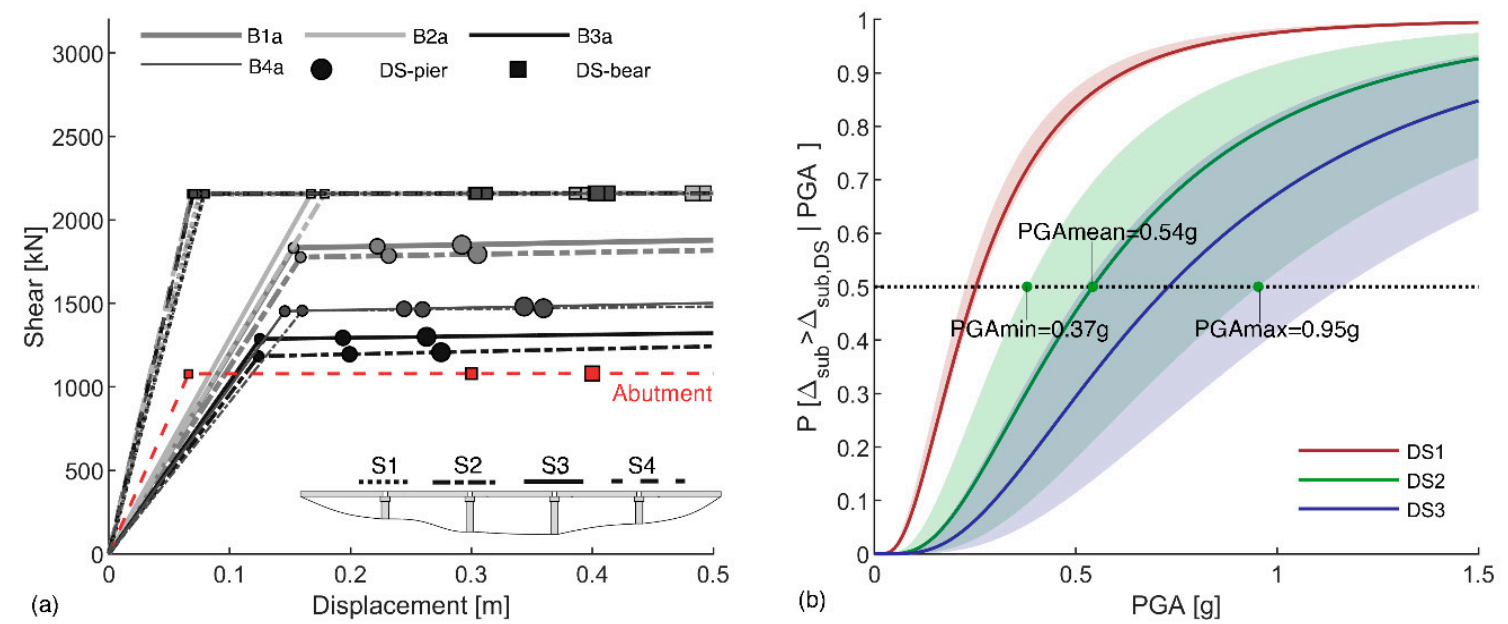

Figure 9. (a) Force displacement laws of the subassemblies of B1a, B2a, B3a, B4a ( $\left.\rho_{t}=0.09 \%\right)$. The subassemblies are indicated with a different line pattern, the index-bridges with different colors and linewidth. (b) Bundles of fragility curves of the main bridge

The seismic assessment is performed according to the IPM. The seismic demand is expressed by elastic response spectra retrieved by the Italian Code for the bridge location and probability of exceedance of $50 \%, 10 \%$ and $5 \%$ in 50 years for the three damage states, respectively. The capacity in terms of PGA $\left(P G A_{C}^{D S}\right)$ is quantified for each subassembly and the minimum is identified as the capacity of the bridge $\left(P G A_{b r i d g e}^{D S}\right)$. This process is repeated for the three damage states. Table 5 reports the value of $P G A_{c}^{D S}$ for the B1a and B2a index-bridges. In both the cases, the subassembly of the abutments and of the shortest piers determine the reaching of the bridge DS1. The subassemblies composed by the central pier are critical in terms of DS2 and DS3 for both the selected index bridges. However, it is evident that the capacity of B1, in which the damage state is achieved for the damage of the pier, is almost a half of the capacity of $\mathrm{B} 2$, in which the neoprene bearings determines the damage state of the subassembly. The $P G A_{\text {bridge }}^{D S}$ for B1a and B2a (evidenced in Table 5) together with the PGA-based capacity for the other index-bridges are used to perform the fragility analysis of the investigated case study bridge in the transverse direction. The fragility of the bridge is represented by the area between the lognormal cumulative density functions having the medians equal to the minimum and maximum PGA ( $P G A_{\min }^{D S}$ and $P G A_{\max }^{D S}$ ) capacity (Figure 9b). For simplicity, the logarithmic standard deviation is assumed equal to 0.7 [60]. Moreover, the thick curves represent the mean fragility curve, whose logarithmic mean $\left(P G A_{\text {mean }}^{D S}\right)$ is the average of the logarithmic PGA values of the single index-bridges.

Table 5. Value of PGA capacity for the subassemblies of the B1 and B2 index-bridges. Bold values represent the PGA-based capacity of the corresponding index-bridge.

\begin{tabular}{|c|c|c|c|c|c|c|c|c|c|c|}
\hline \multirow[t]{2}{*}{ Capacity } & \multicolumn{5}{|c|}{ B1a } & \multicolumn{5}{|c|}{ B2a } \\
\hline & S-ab & S1 & $\mathrm{S} 2$ & S3 & $\mathrm{S} 4$ & S-ab & $\mathrm{S} 1$ & $\mathrm{~S} 2$ & S3 & $\mathrm{S} 4$ \\
\hline$P G A_{c}^{D S 1}$ & 0.26 & 0.27 & 0.32 & 0.32 & 0.26 & 0.26 & 0.27 & 0.37 & 0.36 & 0.26 \\
\hline$P G A_{c}^{D S 2}$ & 1.02 & 1.01 & 0.48 & 0.48 & 1.02 & 1.02 & 1.01 & 0.95 & 0.96 & 1.02 \\
\hline$P G A_{c}^{D S 3}$ & 1.21 & 1.20 & 0.61 & 0.60 & 1.21 & 1.21 & 1.20 & 1.18 & 1.16 & 1.21 \\
\hline
\end{tabular}

The risk is calculated in terms of mean annual frequency of exceeding the limit states $\left(\lambda_{D S}\right)$. The hazard curve for the location of the bridge is retrieved by means of the software REASSESS [70]. Table 6 reports the value of the PGA-capacity, (minimum, maximum and average) and the corresponding value of seismic risk. High variability is registered for the seismic risk at DS2 and DS3. These are caused by the previously described strong variation of the PGA-based capacity depending on the critical component (e.g., piers or neoprene bearings). The mean value of the risk may be implemented in 
bridge management systems and used for risk prioritisation strategy within a bridge portfolio seismic assessment. The wide variation of risk is a proxy to address refined inspections to selected bridges within a bridge portfolio. As an example, this simplified procedure can be applied to analyze the risk of a given dataset of bridges with poor data accounting for epistemic uncertainties; thus targeted inspections (to determine the concrete/steel design strength of the constructive details) can be carried out in the cases in which more variation of risk is registered.

Table 6. Value of PGA-capacity and seismic risk for the considered damage states.

\begin{tabular}{ccccccc}
\hline Damage State & $\boldsymbol{P G A}_{\min }$ & $\boldsymbol{P G} \boldsymbol{A}_{\text {avg }}$ & $\boldsymbol{P G} \boldsymbol{A}_{\max }$ & $\boldsymbol{\lambda}_{\min }\left(\mathbf{1 0}^{-\mathbf{2}}\right)$ & $\boldsymbol{\lambda}_{\text {avg }}\left(\mathbf{1 0}^{\mathbf{- 2}}\right)$ & $\boldsymbol{\lambda}_{\max }\left(\mathbf{1 0}^{-\mathbf{2}}\right)$ \\
\hline DS1 & 0.23 & 0.25 & 0.26 & 0.370 & 0.315 & 0.298 \\
DS2 & 0.38 & 0.58 & 0.95 & 0.165 & 0.080 & 0.031 \\
DS3 & 0.52 & 0.76 & 1.16 & 0.096 & 0.048 & 0.021 \\
\hline
\end{tabular}

\section{Conclusions}

This work is framed in the general context of the data collection and structural safety assessment on existing bridges and viaducts. A methodology to perform inspections of RC bridges by means of Remote Piloted Aircrafts Systems oriented to a photogrammetry-based data collection is described. First, recommendations to perform the in-situ RPAS-data collection are proposed. Then, the procedure to analyze the 2D-images to achieve a 3D point cloud model of the bridge and extract the geometry of the critical components is presented. Moreover, a simplified procedure to calculate the seismic risk given the extracted geometry of the structural components of the bridge is presented. It does not resort to refined FEM approaches and can be applied with low computational effort, together with RPAS-inspections, to map the structural risk of bridge portfolios at road network scale. The procedure considers appropriately the epistemic uncertainties associated to constructive details which are not retrievable from the RPAS inspection by generating a population of index-bridges having the same deterministic data, while varying the uncertain parameters. The seismic performance analysis of the index bridges is performed with a simplified mechanic-based approach suitable for the wide-spread typology of simply-supported RC bridges. The seismic risk is calculated as the mean annual frequency to reach or exceed a given limit state.

The complete procedure, from the RPAS data acquisition to the seismic risk assessment, is applied on a six-spans bridge with RC single column piers and neoprene bearing devices.

The necessary data to perform the seismic risk assessment were arranged in a spreadsheet which is appropriately designed to represent the input data of a MATLAB-based programming routine. The procedure applied on the case study proves that the seismic performance of the analyzed bridge is strongly influenced by the mechanical behavior of both the piers and the bearing devices. This highlights that the RPAS surveys should accurately recognize the typologies and geometry of the deck-substructure connection system in bridges similar to the analyzed case study. Moreover, it is proved that the constructive details (i.e., the amount of steel reinforcements) which normally cannot be detected by visual inspections only, influence considerably the seismic performance of the bridge. The presented procedure can appropriately quantify the range of variability of the seismic risk linked to the epistemic uncertainties and can be applied to address targeted more refined data collections if high risk-based variability is registered.

Further developments should be oriented to enhance the potentialities of the RPAS data collection by means of automatic algorithms to extract and manage data for BIM storage or addressing analytical structural assessment processes. An extension of the procedure can be oriented to consider the degradation condition (which can be in turn included in BIM environment) in the mechanical modeling of the materials and its influence in the seismic fragility. Moreover, the simplified seismic assessment calculation should be tested for simply-supported bridges with different geometry and typology of deck-substructure connection to evaluate their risk and the role of any epistemic uncertainties. It is worth noting that other current-developed simplified assessment approaches suitable for other bridge 
typologies can be easily integrated in the proposed procedure. This will allow setting up a suitable tool to calculate the seismic risk within road networks where a wide variety of bridge typologies is presented.

Author Contributions: Methodology, A.N. and M.S.; validation, A.N., M.S.; investigation, A.N., M.S. and M.N.; data curation, A.N., M.S. and M.N.; writing—original draft preparation, A.N and M.S.; writing-review and editing, A.N and M.S. All authors have read and agreed to the published version of the manuscript.

Funding: The presented research has been partially developed within the framework of the ReLUIS-DPC 2019-2021 research program, funded by Presidenza del Consiglio dei Ministri, Dipartimento della Protezione Civile.

Acknowledgments: This study was conducted as part of the Industrial PhD research program (PON-RI 2014-2020) sponsored by the Italian Ministry of Education, University and Research.

Conflicts of Interest: The authors declare no conflict of interest.

\section{References}

1. Ministero delle Infrastrutture e dei Trasporti. Linee Guida per la Classificazione e Gestione del Rischio, la Valutazione della Sicurezza ed il Monitoraggio dei Ponti Esistenti; Ministero delle Infrastrutture e dei Trasporti, Consiglio Superiore dei Lavori Pubblici: Roma, Italy, 2020.

2. Morgenthal, G.; Hallermann, N.; Kersten, J.; Taraben, J.; Debus, P.; Helmrich, M.; Rodehorst, V. Framework for automated UAS-based structural condition assessment of bridges. Autom. Constr. 2019, 97, 77-95. [CrossRef]

3. Borzi, B.; Ceresa, P.; Franchin, P.; Noto, F.; Calvi, G.M.; Pinto, P.E. Seismic vulnerability of the Italian roadway bridge stock. Earthq. Spectra 2015, 31, 2137-2161. [CrossRef]

4. Sangiorgio, V.; Uva, G.; Fatiguso, F. User Reporting-Based Semeiotic Assessment of Existing Building Stock at the Regional Scale. J. Perform. Constr. Facil. 2018, 32, 04018079. [CrossRef]

5. Porco, F; Fiore, A.; Porco, G.; Uva, G. Monitoring and safety for prestressed bridge girders by SOFO sensors. J. Civil. Struct. Health Monit. 2012, 3, 3-18. [CrossRef]

6. Porco, F.; Uva, G.; Fiore, A.; Mezzina, M. Assessment of concrete degradation in existing structures: A practical procedure. Struct. Eng. Mech. 2014, 52, 701-721. [CrossRef]

7. Uva, G.; Porco, F.; Fiore, A.; Porco, G. Structural monitoring using fiber optic sensors of a pre-stressed concrete viaduct during construction phases. Case Stud. Nondestruct. Test. Eval. 2014, 2, 27-37. [CrossRef]

8. Sangiorgio, V.; Pantoja, J.C.; Varum, H.; Uva, G.; Fatiguso, F. Structural degradation assessment of RC buildings: Calibration and comparison of semeiotic-based methodology for decision support system. $J$. Perform. Constr. Facil. 2019, 33, 04018109. [CrossRef]

9. Uva, G.; Porco, F.; Fiore, A.; Mezzina, M. The assessment of structural concretes during construction phases. Struct. Surv. 2014, 32, 189-208. [CrossRef]

10. Zou, Y.; Gonzalez, V.; Lim, J.; Amor, R.; Guo, B.; Babaeian Jelodar, M. Systematic framework for postearthquake bridge inspection through uav and $3 \mathrm{~d}$ bim reconstruction. In Proceedings of the CIB World Building Congress, Hong Kong, China, 17-21 June 2019; pp. 17-21.

11. Ayele, Y.Z.; Droguett, E. Application of UAVs for bridge inspection and resilience assessment. In Proceedings of the 29th European Safety and Reliability Conference, Hannover, Germany, 22-26 September 2019; pp. 1328-1335.

12. Barrile, V.; Candela, G.; Fotia, A.; Bernardo, E. UAV survey of bridges and viaduct: Workflow and application. In Proceedings of the 19th International Conference on Computational Science and Its Applications, Saint Petersburg, Russia, 1-4 July 2019; Misra, S., Gervasi, O., Murgante, B., Stankova, E., Korkhov, V., Torre, C., Rocha, A.C.A.M., Taniar, D., Apduhan, O.B., Tarantino, E., Eds.; Springer: Cham, Switzerland, 2019; pp. 269-284.

13. Duque, L.; Seo, J.; Wacker, J. Synthesis of Unmanned Aerial Vehicle Applications for Infrastructures. J. Perform. Constr. Facil. 2018, 32, 04018046. [CrossRef]

14. Chan, B.; Guan, H.; Jo, J.; Blumenstein, M. Towards UAV-based bridge inspection systems: A review and an application perspective. Struct. Monit. Maint. 2015, 2, 283-300. [CrossRef]

15. Seo, J.; Duque, L.; Wacker, J. Drone-enabled bridge inspection methodology and application. Autom. Constr. 2018, 94, 112-126. [CrossRef] 
16. Otero, L.D. Proof of Concept for Using Unmanned Aerial Vehicles for High Mast Pole and Bridge Inspections; No. BDV28-977-02; Florida Department of Transportation, Research Center: Tallahassee, FL, USA, 2015.

17. Lee, K.W.; Park, J.K. Modeling and Management of Bridge Structures Using Unmanned Aerial Vehicle in Korea. Sens. Mater. 2019, 31, 3765-3772. [CrossRef]

18. Khaloo, A.; Lattanzi, D.; Cunningham, K.; Dell'Andrea, R.; Riley, M. Unmanned aerial vehicle inspection of the Placer River Trail Bridge through image-based 3D modelling. Struct. Infrastruct. Eng. 2018, 14, 124-136. [CrossRef]

19. Castellazzi, G.; D’Altri, A.M.; Bitelli, G.; Selvaggi, I.; Lambertini, A. From Laser Scanning to Finite Element Analysis of Complex Buildings by Using a Semi-Automatic Procedure. Sensors 2015, 15, 18360-18380. [CrossRef] [PubMed]

20. Lubowiecka, I.; Armesto, J.; Arias, P.; Lorenzo, H. Historic bridge modelling using laser scanning, ground penetrating radar and finite element methods in the context of structural dynamics. Eng. Struct. 2009, 31, 2667-2676. [CrossRef]

21. ENAC. Regolamento Mezzi Aerei a Pilotaggio Remoto, 3rd ed.; ENSC: Roma, Italy, 2019.

22. Commission Implementing Regulations (EU) 2019/947. Rules and Procedures for the Operation of Unmanned Aircraft; Official Journal of the European Union (OJ): Bruxelles, Belgium, 2019.

23. Darby, P.; Hollerman, W.; Miller, J. Exploring the Potential Utility of Unmanned Aerial Vehicles for Practical Bridge Inspection in Louisiana. MATEC Web Conf. 2019, 271, 01001. [CrossRef]

24. Kubota, S.; Ho, C.; Nishi, K. Construction and usage of three-dimensional data for road structures using terrestrial laser scanning and UAV with photogrammetry. In Proceedings of the 36th International Symposium on Automation and Robotics in Construction and Mining, Banff, AB, Canada, 21-24 May 2019.

25. Gómez-López, J.M.; Pérez-García, J.L.; Mozas-Calvache, A.T.; Delgado-García, J. Mission Flight Planning of RPAS for Photogrammetric Studies in Complex Scenes. ISPRS Int. J. Geo-Inf. 2020, 9, 392.

26. Flores-de-Santiago, F.; Valderrama-Landeros, L.; Rodríguez-Sobreyra, R.; Flores-Verdugo, F. Assessing the effect of flight altitude and overlap on orthoimage generation for UAV estimates of coastal wetlands. J. Coast. Conserv. 2020, 24, 35. [CrossRef]

27. Sanz-Ablanedo, E.; Chandler, J.H.; Ballesteros-Pérez, P.; Rodríguez-Pérez, J.R. Reducing systematic dome errors in digital elevation models through better UAV flight design. Earth Surf. Process. Landf. 2020, 45, 2134-2147. [CrossRef]

28. Pan, Y.; Dong, Y.; Wang, D.; Chen, A.; Ye, Z. Three-Dimensional Reconstruction of Structural Surface Model of Heritage Bridges Using UAV-Based Photogrammetric Point Clouds. Remote Sens. 2019, 11, 1204. [CrossRef]

29. Eltner, A.; Sofia, G. Chapter 1-Structure from motion photogrammetric technique. In Developments in Earth Surface Processes; Tarolli, P., Mudd, S.M., Eds.; Elsevier: Amsterdam, The Netherlands, 2020; Volume 23, pp. 1-24.

30. Anderson, K.; Westoby, M.J.; James, M.R. Low-budget topographic surveying comes of age: Structure from motion photogrammetry in geography and the geosciences. Prog. Phys. Geogr. Earth Environ. 2019, 43, 163-173. [CrossRef]

31. Padró, J.-C.; Muñoz, F.-J.; Planas, J.; Pons, X. Comparison of four UAV georeferencing methods for environmental monitoring purposes focusing on the combined use with airborne and satellite remote sensing platforms. Int. J. Appl. Earth Obs. Geoinf. 2019, 75, 130-140. [CrossRef]

32. Pérez, J.A.; Gonçalves, G.R.; Charro, M.C. On the positional accuracy and maximum allowable scale of UAV-derived photogrammetric products for archaeological site documentation. Geocarto Int. 2019, 34, 575-585. [CrossRef]

33. Jaud, M.; Passot, S.; Allemand, P.; Le Dantec, N.; Grandjean, P.; Delacourt, C. Suggestions to Limit Geometric Distortions in the Reconstruction of Linear Coastal Landforms by SfM Photogrammetry with PhotoScan ${ }^{\circledR}$ and MicMac ${ }^{\circledR}$ for UAV Surveys with Restricted GCPs Pattern. Drones 2019, 3, 2. [CrossRef]

34. Saponaro, M.; Turso, A.; Tarantino, E. Parallel development of comparable photogrammetric workflows based on UAV data inside SW platforms. In Proceedings of the International Conference on Computational Science and Its Applications, Cagliari, Italy, 1-4 July 2020.

35. Tmušić, G.; Manfreda, S.; Aasen, H.; James, M.R.; Gonçalves, G.; Ben-Dor, E.; Brook, A.; Polinova, M.; Arranz, J.J.; Mészáros, J.; et al. Current Practices in UAS-based Environmental Monitoring. Remote Sens. 2020, 12, 1001. [CrossRef] 
36. Zhou, Y.; Rupnik, E.; Meynard, C.; Thom, C.; Pierrot-Deseilligny, M. Simulation and Analysis of Photogrammetric UAV Image Blocks-Influence of Camera Calibration Error. Remote Sens. 2020, 12, 22. [CrossRef]

37. Lowe, G. SIFT-the scale invariant feature transform. Int. J. 2004, 2, 91-110.

38. Barba, S.; Barbarella, M.; Di Benedetto, A.; Fiani, M.; Limongiello, M. Quality Assessment of UAV Photogrammetric Archaeological Survey. Int. Arch. Photogramm. Remote Sens. Spat. Inf. Sci. 2019, XLII-2/W9, 93-100. [CrossRef]

39. Rangel, J.M.G.; Gonçalves, G.R.; Pérez, J.A. The impact of number and spatial distribution of GCPs on the positional accuracy of geospatial products derived from low-cost UASs. Int. J. Remote Sens. 2018, 39, 7154-7171. [CrossRef]

40. Saponaro, M.; Capolupo, A.; Tarantino, E.; Fratino, U. Comparative analysis of different UAV-based photogrammetric processes to improve product accuracies. In Proceedings of the 19th International Conference on Computational Science and Its Applications, Saint Petersburg, Russia, 1-4 July 2019; Misra, S., Gervasi, O., Murgante, B., Stankova, E., Korkhov, V., Torre, C., Rocha, A.C.A.M., Taniar, D., Apduhan, O.B., Tarantino, E., Eds.; Springer: Cham, Switzerland, 2019; pp. 225-238.

41. James, M.R.; Antoniazza, G.; Robson, S.; Lane, S.N. Mitigating systematic error in topographic models for geomorphic change detection: Accuracy, precision and considerations beyond off-nadir imagery. Earth Surf. Process. Landf. 2020, 45, 2251-2271. [CrossRef]

42. Saponaro, M.; Tarantino, E.; Reina, A.; Furfaro, G.; Fratino, U. Assessing the Impact of the Number of GCPS on the Accuracy of Photogrammetric Mapping from UAV Imagery. Balt. Surv. 2019, 10, 43-51.

43. Casella, V.; Chiabrando, F.; Franzini, M.; Manzino, A.M. Accuracy Assessment of a Photogrammetric UAV Block by using Different Software and Adopting Diverse Processing Strategies. In Proceedings of the 5th International Conference on Geographical Information Systems Theory, Applications and Management (GISTAM 2019), Heraklion, Greece, 3-5 May 2019; pp. 77-87.

44. Isailović, D.; Petronijević, M.; Hajdin, R. The future of BIM and Bridge Management Systems. In Proceedings of the IABSE Symposium 2019: Towards a Resilient Built Environment-Risk and Asset Management, Guimaraes, Portugal, 27-29 March 2019; pp. 1673-1680.

45. Wu, J.; Zhang, J. New Automated BIM Object Classification Method to Support BIM Interoperability. J. Comput. Civil. Eng. 2019, 33, 04019033. [CrossRef]

46. Iglesias, J.L.; Severiano, J.A.D.; Amorocho, P.E.L.; del Val, C.M.; Gómez-Jáuregui, V.; García, O.F.; Royano, A.P.; González, C.O. Revision of Automation Methods for Scan to BIM.; Springer: Cham, Switzerland, 2019; pp. $482-490$.

47. Wang, C.; Cho, Y.K.; Kim, C. Automatic BIM component extraction from point clouds of existing buildings for sustainability applications. Autom. Constr. 2015, 56, 1-13. [CrossRef]

48. Yang, L.; Cheng, J.C.P.; Wang, Q. Semi-automated generation of parametric BIM for steel structures based on terrestrial laser scanning data. Autom. Constr. 2020, 112, 103037. [CrossRef]

49. Barrile, V.; Candela, G.; Fotia, A. Point cloud segmentation using image processing techniques for structural analysis. ISPRS Int. Arch. Photogramm. Remote Sens. Spat. Inf. Sci. 2019, XLII-2/W11, 187-193. [CrossRef]

50. Pinto, P.E.; Franchin, P. Issues in the upgrade of Italian highway structures. J. Earthq. Eng. 2010, 14, 1221-1252. [CrossRef]

51. Raffaele, D.; Porco, F.; Fiore, A.; Uva, G. Simplified vulnerability assessment of reinforced concrete circular piers in multi-span simply supported bridges. Struct. Infrastruct. Eng. 2014, 10, 950-962. [CrossRef]

52. Gentile, R.; Nettis, A.; Raffaele, D. Effectiveness of the displacement-based seismic performance assessment for continuous RC bridges and proposed extensions. Eng. Struct. 2020, 221, 110910. [CrossRef]

53. Uva, G.; Ciampoli, P.; Leggieri, V.; Nettis, A.; Ruggieri, S. A mechanical approach for estimating regional fragility curves of existing RC buildings stock in Puglia. In Proceedings of the 7th International Conference on Computational Methods in Structural Dynamics and Earthquake Engineering (COMPDYN 2019), Hersonissos, Greece, 24-26 June 2019.

54. Aiello, M.A.; Ciampoli, P.L.; Fiore, A.; Perrone, D.; Uva, G. Influence of infilled frames on seismic vulnerability assessment of recurrent building typologies. Ing. Sismica 2017, 34, 58-80.

55. Gentile, R.; Porco, F.; Raffaele, D.; Uva, G. Simplified moment-curvature relationship in analytical form for circular RC sections. Bull. N. Z. Soc. Earthq. Eng. 2018, 51, 145-158. [CrossRef]

56. Gentile, R.; Raffaele, D. Simplified analytical Moment-Curvature relationship for hollow circular RC cross-sections. Earthq. Struct. 2018, 15, 419-429. [CrossRef] 
57. Priestley, M.J.N.; Calvi, G.M.; Kowalsky, M.J. Displacement-Based Seismic Design of Structures. Earthq. Spectra 2007, 24, 1-24.

58. Cardone, D. Displacement limits and performance displacement profiles in support of direct displacement-based seismic assessment of bridges. Earthq. Eng. Struct. Dyn. 2014, 43, 1239-1263. [CrossRef]

59. Priestley, M.J.N.; Seible, F.; Calvi, G.M. Seismic Design and Retrofit of Bridges; John Wiley \& Sons: Hoboken, NJ, USA, 1996.

60. Nettis, A.; Gentile, R.; Uva, G.; Raffaele, D. Some applications of a displacement-based procedure for the seismic response of continuous girder RC-bridges. In Proceedings of the 3rd International Conference on International Conference on Recent Advances in Nonlinear Design, Resilience and Rehabilitation of Structures (CoRASS 2019), Coimbra, Portugal, 16-18 October 2019.

61. Ramanathan, K.; Desroches, R.; Padgett, J.E. Analytical Fragility Curves for Multispan Continuous Steel Girder Bridges in Moderate Seismic Zones. Transp. Res. Rec. J. Transp. Res. Board 2010, 2202, 173-182. [CrossRef]

62. Cornell, C.A.; Jalayer, F.; Hamburger, R.O.; Foutch, D.A. Probabilistic basis for 2000 SAC federal emergency management agency steel moment frame guidelines. J. Struct. Eng. 2002, 128, 526-533. [CrossRef]

63. Decreto Ministeriale 3 Marzo 1975. Approvazione delle Norme Tecniche per le Costruzioni in Zone Sismiche; G.U. 8-4-1975, n.93; Consiglio Superiore dei Lavori Pubblici: Roma, Italy, 1975.

64. Capolupo, A.; Saponaro, M.; Borgogno Mondino, E.; Tarantino, E. Combining Interior Orientation Variables to Predict the Accuracy of Rpas-Sfm 3D Models. Remote Sens. 2020, 12, 2674. [CrossRef]

65. Barrile, V.; Fotia, A.; Candela, G.; Bernardo, E. Integration of 3D model from UAV survey in BIM environment. ISPRS Int. Arch. Photogramm. Remote Sens. Spat. Inf. Sci. 2019, XLII-2/W11, 195-199. [CrossRef]

66. Uva, G.; Sanjust, C.A.; Casolo, S.; Mezzina, M. ANTAEUS Project for the Regional Vulnerability Assessment of the Current Building Stock in Historical Centers. Int. J. Archit. Herit. 2016, 10, 20-43. [CrossRef]

67. MATLAB, Version 9.5.0.944444 (R2018b); The MathWorks Inc.: Natick, MA, USA, 2018.

68. Cardone, D.; Perrone, G.; Sofia, S. A performance-based adaptive methodology for the seismic evaluation of multi-span simply supported deck bridges. Bull. Earthq. Eng. 2011, 9, 1463-1498. [CrossRef]

69. Montejo, L.A.; Kowalsky, M.J. Set of Codes for the Analysis of Reinforced Concrete Members; North Carolina State University: Railegh, NC, USA, 2007.

70. Chioccarelli, E.; Cito, P.; Iervolino, I.; Giorgio, M. REASSESS V2.0: Software for single- and multi-site probabilistic seismic hazard analysis. Bull. Earthq. Eng. 2019, 17, 1769-1793. [CrossRef] 